University of San Diego

Digital USD

2018-05-26

\title{
Identification of Nurse-Controlled Predictors of Pain in Patients Undergoing a Total Hip or Total Knee Arthroplasty
}

Melodie Ruth Daniels

University of San Diego

Follow this and additional works at: https://digital.sandiego.edu/dissertations

Part of the Nursing Commons

\section{Digital USD Citation}

Daniels, Melodie Ruth, "Identification of Nurse-Controlled Predictors of Pain in Patients Undergoing a Total Hip or Total Knee Arthroplasty" (2018). Dissertations. 112.

https://digital.sandiego.edu/dissertations/112

This Dissertation: Open Access is brought to you for free and open access by the Theses and Dissertations at Digital USD. It has been accepted for inclusion in Dissertations by an authorized administrator of Digital USD. For more information, please contact digital@sandiego.edu. 


\title{
UNIVERSITY OF SAN DIEGO \\ Hahn School of Nursing in Health Science \\ DOCTOR OF PHILOSOPHY IN NURSING
}

\author{
Identification of Nurse-Controlled Predictors of Pain in Patients Undergoing a \\ Total Hip or Total Knee Arthroplasty \\ by \\ Melodie Ruth Daniels
}

A dissertation presented to the

FACULTY OF THE HAHN SCHOOL OF NURSING AND HEALTH SCIENCE UNIVERSITY OF SAN DIEGO

\begin{abstract}
In partial fulfillment of the requirements for the degree
DOCTOR OF PHILOSPHY OF NURSING
\end{abstract}

May 2018

\author{
Dissertation Committee \\ Cynthia D. Connelly, PhD, RN, FAAN, Chair \\ Jane M. Georges, PhD, RN \\ Ruth A. Bush, PhD, MPH
}




\section{UNIVERSITY OF SAN DIEGO}

Hahn School of Nursing and Health Science

DOCTOR OF PHILOSOPHY IN NURSING

CANDIDATE'S NAME:

TITLE OF DISSERTATION:
Melodie Ruth Daniels

Identification of Nurse-Controlled

Predictors of Pain in Patients Undergoing a Total Hip or Total Knee Arthroplasty

DISSERTATION COMMITTEE:

Cynthia D. Connelly, PhD, RN, FAAN

Chairperson

Jane M. Georges PhD, RN

Committee Member

Ruth A. Bush, PhD, MPH

Committee Member 


\begin{abstract}
Objectives: The purpose of this study was to examine relationships among nursing interventions and pain status during hospitalization in orthopedic surgical patients receiving total hip or knee arthroplasty in one of four community hospitals in San Diego, California.
\end{abstract}

Background: The epidemic of opioid-related adverse events creates a need for opioid sparing approaches to pain management. Pain management practices have been studied in relation to medicine; however, the relationship between pain and opioid sparing, nursespecific interventions is not clear.

Methods: The retrospective descriptive study examined Electronic Health Record (EHR) data of patients $(N=1657)$ discharged after a total hip or knee arthroplasty from one of four community hospitals between March 1, 2016 and April 30, 2017. Data extracted included patients’ sociodemographic characteristics, daily morphine equivalent, average time between nursing pain assessments, actual and acceptable levels of pain, and use of adjunct therapy. Descriptive and inferential statistics were used to describe the sample and examine relationships between variables. Binomial logistic regression was utilized to identify factors that increased the likelihood of controlled pain during hospitalization for the study sample.

Results: Approximately two-thirds (65.3\%) of patients had their pain controlled during hospitalization; the average daily morphine equivalent day 2 post op was $1.25 \mathrm{mg}$ ( $S D=$ 1.03) for the overall sample, and $1.28 \mathrm{mg}(S D=1.08)$ for those with controlled pain; slightly over one-fourth (26.8\%) used aromatherapy during hospitalization. Significant group differences between patients reporting controlled vs. uncontrolled pain during 
hospitalization were found in patients' age, BMI, surgeon, time between nurse pain assessments, sedation status, nerve block, aromatherapy and comfort massage use. Logistic regression indicated patients with lower BMI, longer time between nurse pain assessments on day 2 post op, received aromatherapy during hospitalization, and a nerve block were more likely to have controlled pain during hospitalization, $\chi^{2}(14)=122.47, p$ $<.001$. Patients whose surgeons conducted less than 60 or more than 89 surgeries during the study and patients who were not lightly drowsy or easy to arouse were more likely to experience uncontrolled pain during hospitalization.

Conclusions: The daily morphine equivalent administered to patients on day two post op and during hospitalization was not significantly different for patients with controlled vs. uncontrolled pain. The results of this study show patients with controlled pain are using adjunct therapies more than those with uncontrolled pain during hospitalization; more information is needed regarding the reasons patients with uncontrolled pain are not using adjunct therapy. Pain level and lack of readily available adjunct therapies may present overwhelming barriers to patients with uncontrolled pain.

Implications: Nurse-controlled variables empower nurses to improve patient care while decreasing patients' risk for post-surgical opioid-related complications and addictions. Future research is needed to clarify patients' and nurses' perspectives in pain treatments and variability. 
(C) Copyright by Melodie Daniels

All Rights Reserved

2018 


\section{Dedication}

This work is dedicated to my loving family and friends who have given me the strength to contribute more in life. To my dear husband, Keith Daniels, who has been my human-rock in life. I dedicate my work to my children and grandchildren as light to their path. My prayer is for them to dream passionately and fulfil their heartfelt dreams. My dear family and friends are too numerous to mention each by name; however, I am forever grateful to them for their unconditional love, continual encouragement, and pure sacrifices.

Most important, I am grateful for God's love and grace which has sustained me from my unlikely conception to birth and throughout each day of my life. I am grateful for God's guidance, protection, and each breath given to fulfill his perfect will in my life. 


\section{Acknowledgments}

I would like to think the University of San Diego (USD) faculty, colleagues, friends, and family who have contributed to this research study and my evolution in the doctoral program. This journey has been both inspiring and life-changing.

I am deeply grateful to my dissertation chair, Dr. Connelly. Her selfless guidance has not only been spot on, it has gotten me through some very difficult times. Dr. Connelly’s ability to see the bottom line, “it’s only a dissertation,” brought me the clarity I needed to finish. Her beautiful, dry sense of humor kept me laughing as I finished what seem to be insurmountable task. Dr. Connelly gave me the courage to evolve. In addition to my dissertation chair, I am deeply grateful to the members of my dissertation committee. Dr. Bush, a brilliant teacher and friend throughout my time in USD. I cannot imagine learning statistics from anyone other than Dr. Bush. Her words, "it depends” and “did you do what I taught you,” ring in my ears as I consider each result. I am also deeply grateful to Dr. Georges. Her influence on my life and future work is more than just significant. Dr. Georges has been a positive force in my development both as a nurse and personally. I now clearly know that "context matters.” She has changed my gaze in life. I will always carry her in my heart. I am deeply grateful.

I would like to thank the organizations who have provided financial support, encouragement, and leadership to help me realize my dream of completing my doctoral study. I am deeply grateful to the Jonas family for the Jonas Nursing Scholarships. It is a prestigious honor to be named Jonas Scholar and I intend to give back in appreciation of this family's support. Without your valuable support, it would not have been possible to complete this dissertation. 
I would like to think Sharp Healthcare for their generous support as recipient of the Marion Hubbard and Center of Nursing Excellence scholarships. They have truly achieved their vision of being the "Best place to work." Sharp Healthcare’s commitment to nursing scholarship is unprecedented in our community. I am grateful to be among the many amazing scholars at Sharp Healthcare. I am grateful to Mary Ellington for graciously sponsoring my study and providing insight to the data, on a moment's notice. I am grateful to Laurie Ecoff for her leadership and encouragement. I am grateful to Louise White, my CNO, who gave me the space to develop.

I want to thank my family who have loved me through everything. To my husband who washed the dishes and my clothes so I could study. To my loving son, Christopher Varner, who gives me unconditional love and acceptance with a unique sense of humor that has kept me laughing since his birth. To my cherished daughter, Melodie Ellen Daniels, who has a smile and personality that brightens every day. My brilliant daughter, Gina Varner, has brought so much love and joy to me. My grandson, Noah Varner, who brings love, humor, and brilliance to each day. My parents, John and Ruth Begnaud, who gave all they had to raise seven strong-willed children, of which I was the first. My sweet Sister, Susan Kelly, who cared for my parents so I could study. I am grateful for her loving, generous heart which shares my conviction that parents should never be abandoned.

Last and most importantly, I am grateful to God who sustains me through each day. God's grace has allowed me to finish this work and will carry me through all of my future endeavors. 


\section{Table of Contents}

CHAPTER I: INTRODUCTION .................................................................

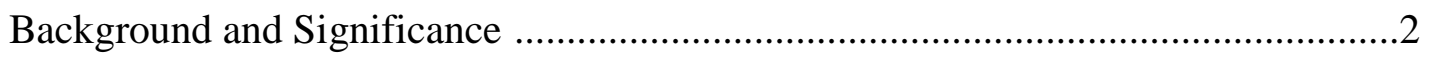

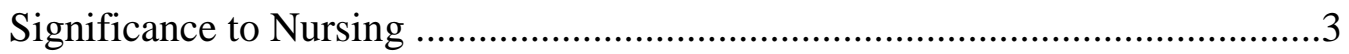

Purpose and Specific Aims .............................................................................

Theoretical Models and Conceptual Framework .................................................4

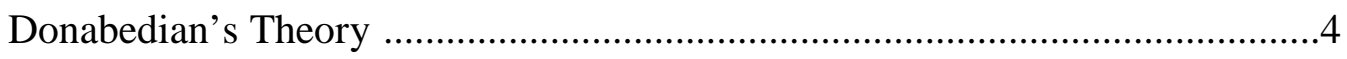

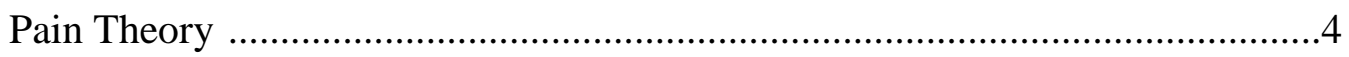

Study Conceptual Framework ...........................................................

CHAPTER II: LITERATURE REVIEW .....................................................

A Revised Nursing Approach to Pain Management in an Era of Patient Harm .......7

Historical Perspective of Pain Practices and Policy ............................................8

Alternatives to Pain Control Practices in an Era of Opioid Addiction .......................10

Voluntary vs. Mandatory Opioid Controls ...................................................10

Projected Outcome of Mandated Opioid Controls ...........................................12

The Role of Nurses in Opioid Reduction .........................................................13

Nurse-Controlled Opioid Reductions vs. Historical Pain Management Practices

Improved Nursing Outcomes .................................................................17

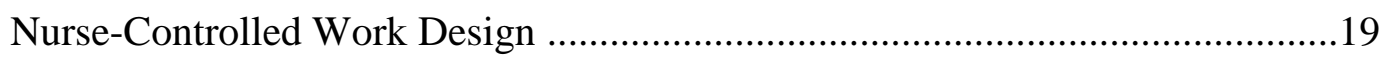

Introduction to the Concept of Standardized Work .............................................19

Standardized Work Concept Background ....................................................20

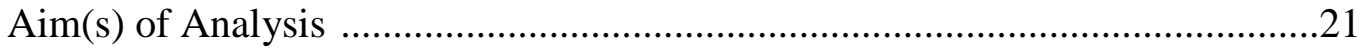




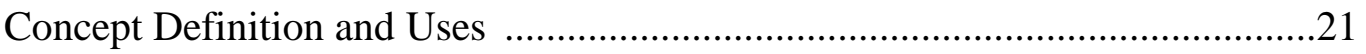

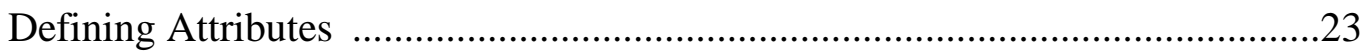

Constructed Cases …............................................................................27

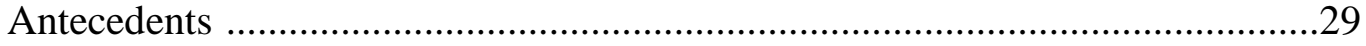

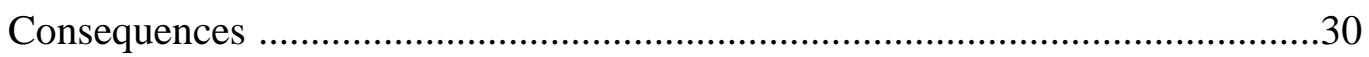

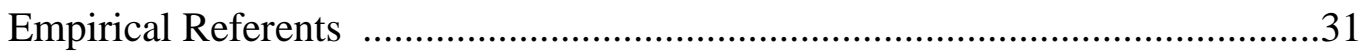

Use of Standardized Work Concept for Pain ...................................................31

Concept Operationalization of Controlled Pain .................................................32

Historical Perspective of Pain ...................................................................32

Theoretical and Operational Definitions ......................................................34

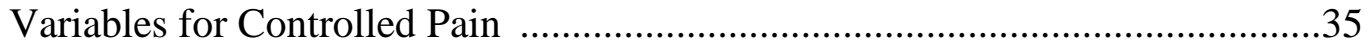

Electronic Health Record Data ...............................................................37

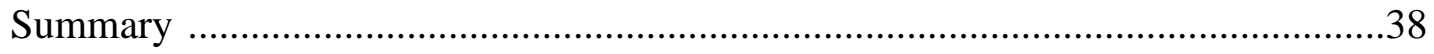

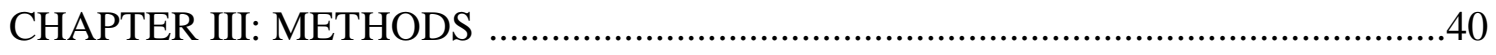

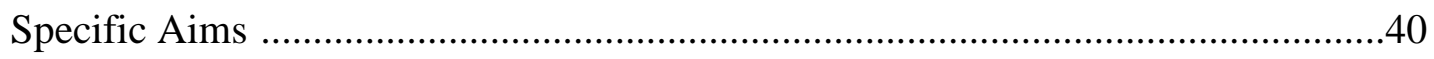

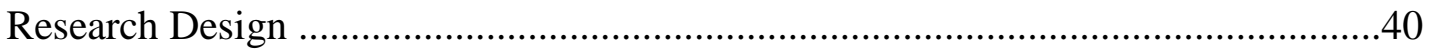

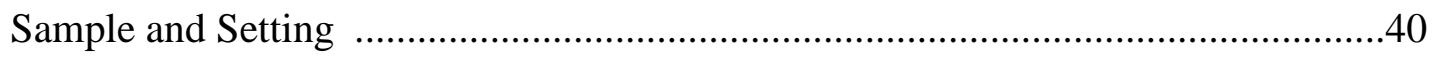

Description of the Four Acute Care Hospitals ................................................41

Data Collection and Management .................................................................42

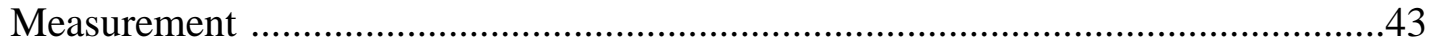

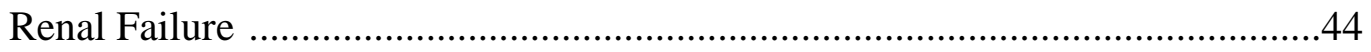

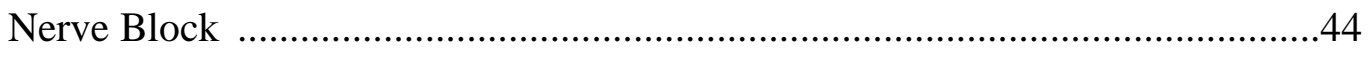

Morphine Equivalent ..........................................................................45 
First Ambulation

First Pasero Opioid Sedation Scale (POSS) ...............................................45

Time Between Nursing Pain Assessments (NPAs) ........................................47

Surgeon

Human Subjects Protection .............................................................................49

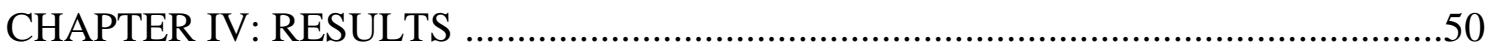

Sociodemographic and Clinical Characteristics of Study Population .....................50

Sociodemographic and Clinical Characteristics of Study Population by Pain

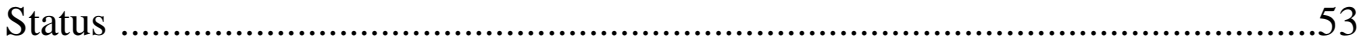

Predictors of Controlled Pain .....................................................................59

Adjunct Therapy Use ..........................................................................62

Adjunct Therapy Use by Pain Status ...........................................................63

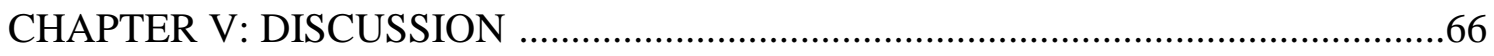

Synthesis of Findings for Research Aims .....................................................67

Sociodemographic and Clinical Characteristics of Study Population ................67

Sociodemographic and Clinical Characteristics of Study Population by

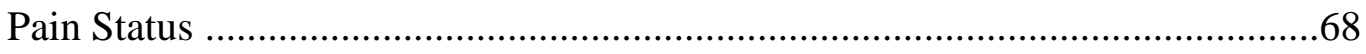

Relationships among Sociodemographic and Clinical Characteristics ..............69

Identification of Factors that Increase the Likelihood of Controlled Pain ..........74

Limitations and Strengths of the Study ….....................................................76

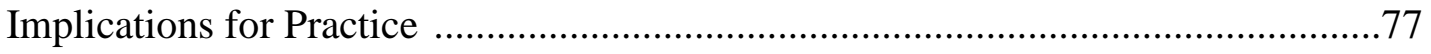

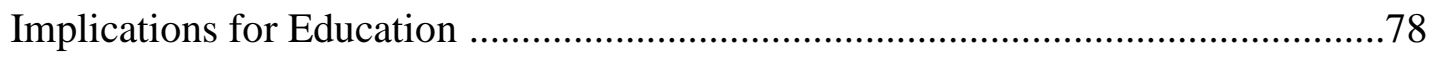

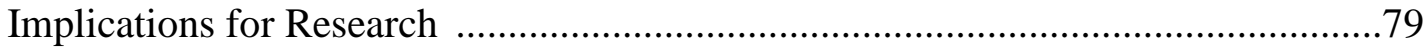




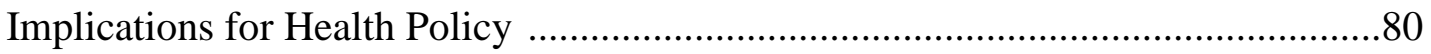

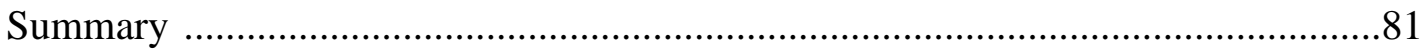

Conclusion

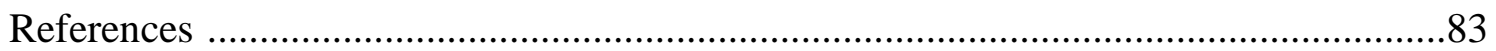




\section{List of Tables}

Table 1. Description of Pasero Opioid-Induced Sedation Scale with Interventions .47

Table 2. Sociodemographic and Clinical Characteristics of Study Population $(N=1657)$ .51

Table 3. Pain Management Interventions after Total Hip or Knee Arthroplasty

$(N=1657)$ .52

Table 4. Differences in Pain during Hospitalization after Total Hip or Knee Arthroplasty: Chi-square $(N=1657)$ .54

Table 5. Differences in Pain Status during Hospitalization after Total Hip or Knee Arthroplasty: One-Way ANOVA $(N=1657)$

Table 6. Prevalence of Patients’ Pain Status during Hospitalization after Total Hip or Knee Arthroplasty by Surgeon $(N=1629)$ .58

Table 7. Prevalence of Patients' Pain Status during Hospitalization after Total Hip or Knee Arthroplasty by Surgeon Experience $(N=1629)$ .59

Table 8. Logistic Regression Analysis Predicting Pain Status during Hospitalization after Total Hip or Knee Arthroplasty $(N=1192)$ 61

Table 9. Adjunct Therapy Use during Hospitalization after Total Hip or Knee Arthroplasty $(N=2005)$

Table 10. Adjunct Therapy Use during Hospitalization by Pain Status after Total Hip or Knee Arthroplasty $(N=1657)$ .64 


\section{List of Figures}

Figure 1: Study Conceptual Framework ...............................................................6

Figure 2: Prevalence of Patients Reporting Controlled Pain vs. Uncontrolled Pain ......59

Figure 3: Adjunct Therapy Use by Pain Status .....................................................65 


\section{List of Appendices}

Appendix A: Standardized Work Concept ................................................................99

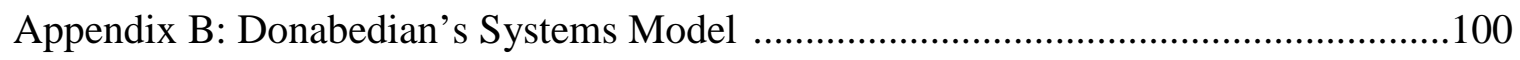

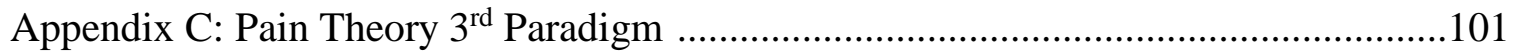

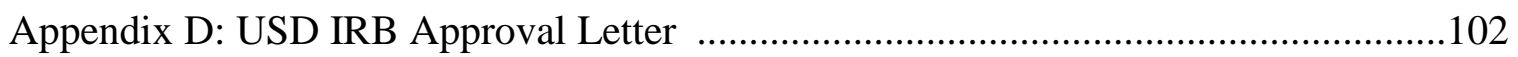




\section{CHAPTER I \\ INTRODUCTION}

A new paradigm in pain management has arisen due to a human-made epidemic of opioid-related addiction and death. In 2016, approximately 76 opioid-related deaths occurred in the United States each day, with more than half of these from prescribed medications (Elkins, 2016). Patients with chronic pain often receive maximum doses of opioid analgesics prior to necessary surgical procures, resulting in difficulty managing post-surgical pain (U. S. Food and Drug Administration [FDA], 2016; Jarzyna et al., 2011). Practice revisions are required to facilitate an opioid-sparing approach in the management of pain (Dowell, Haegerich, \& Chou, 2016; Jarzyna et al., 2011; Otten \& Dunn, 2011; Raffa \& Pergolizzi, 2014; Vargas-Schaffer, 2010). Nurse-related pain management practices have been studied in relation to medicine and use of powerful analgesics; however, the relationships between pain management and nurse-specific indicators are not clear (Carroll et al., 1999; Wu \& Raja, 2011).

The Institutes of Medicine report, The Future of Nursing: Leading Change, Advancing Health, asserts patient safety and quality improvement efforts are dependent on a strong nursing voice as part of an interprofessional healthcare team (IOM, 2011). Systems engineering informs all nursing roles, including clinical practice, and supports effective complex decision-making ability and problem-solving strategies, for instance standardized work (Cassel \& Saunders, 2014). Decreasing variation in pain management through standardized work provides opportunities to optimize pain management (Choinière \& Watt-Watson, 2014; Toussaint \& Berry, 2013). Although it is not possible to standardize every aspect of nursing care, it may be possible to decrease variation in 
pain and inform standardized nursing work to manage pain (Ben-Tovim et al., 2007; Graban, 2011; Kalisch, 2015; Appendix A).

\section{Background and Significance}

In 2000, the Joint Commission (then known as the Joint Commission on Accreditation of Hospital Organizations [JCAHO]) embarked on a nationwide campaign to revise pain management practices. Appropriate pain management became the focus of healthcare providers’ practices and increased litigation for failure to provide adequate treatment (Berry \& Dahl, 2000a, 2000b; McCaffery, 1998; McCaffery \& Pasero, 1997). As part of an interprofessional team, nurses, surgeons, and pharmacists were challenged with management of pain. As the team member closest to the delivery of patient care, hospital nurses were encouraged to take a proactive approach to ensure all patients were immediately assessed and treated for pain without fear of causing addictions as sequela to opioid therapy (Berry \& Dahl, 2000a, 2000b; Ventura, 1999). In the decade following, deaths from unintentional opioid overdose closely paralleled the amount of opioids ordered. Increased availability and inaccurate perception of the safety of prescription medications was associated with opioid-related morbidity and mortality (Pon, Awuah, Curi, Okyere, \& Stern, 2016; Tormoehlen, Mowry, Bodle, \& Rusyniak, 2011). Recently, new practices, guidelines, and political mandates have been introduced to restrict the use of opioids (Cahana, Dansie, Theodore, Wilson, \& Turk, 2013; Dowell et al., 2016; FDA, 2016; Franklin et al., 2015).

Nurses guide opioid utilization through their ability to assess the patient, evaluate choices for pain management, question specific medications, and consider alternatives (Berry \& Dahl, 2000a, 2000b; Curtiss, 2001; Ventura, 1999). Contrary to previous belief 
that opioid utilization in the hospital setting was not related to increased addiction upon discharge, new evidence suggests patients with risk factors for addiction may become addicted with a few opioid doses (Dowell et al., 2016; Elkins, 2016; Pon et al., 2016). Nurses may reduce variation in pain through improved assessment times, multimodal analgesia, management of patient expectations, and adjuvant therapies with proven efficacy to treat pain (Jarzyna et al., 2011; Vargas-Schaffer \& Cogan, 2014).

\section{Significance to Nursing}

Many studies have examined the relationship of various analgesics and their efficacy in managing surgical pain; however, an effective standardized nursing process for pain management has not been realized. Nurses are well positioned to optimize nursespecific pain management approaches and make a significant contribution to prevent the perpetuation of the opioid crisis in the United States.

\section{Purpose and Specific Aims}

The purpose of this study was to examine relationships among nursing interventions and pain status during hospitalization in orthopedic surgical patients. The specific aims are (1) to describe the sociodemographic and clinical characteristics of a sample of orthopedic surgical patients after total hip or knee arthroplasty receiving services in one of four community hospitals in San Diego, California; (2) to examine relationships among the sociodemographic and clinical characteristics, in terms of pain status (controlled vs. uncontrolled pain), for the study sample; and (3) to identify the factors that increase the likelihood of controlled pain during hospitalization for the study sample. 


\section{Theoretical Models and Conceptual Framework}

\section{Donabedian's Theory}

Donabedian's theory of Structure, Process, and Outcome (SPO) informs the connections between the structure of four community hospitals' orthopedic units and culture of the nursing care delivery indicated by skill and balanced by medical care and patient demographics. The process is directly related to nursing assessments and interventions. Patient outcomes are expected to vary according to the structure and processes of nursing care delivery (Donabedian, 2003; Appendix B).

\section{Pain Theory}

Nursing pain theory (Good, 2004) further informs the study; specifically, the theoretical underpinnings of the $3^{\text {rd }}$ Paradigm: Integrated Prescriptive Approaches informs the connections between multimodal interventions and attentive care as opioid sparing approaches to pain management (MY, 2015; Otten \& Dunn, 2011; Vaajoki, Pietilä, Kankkunen, \& Vehviläinen-Julkunen, 2012). This research focuses on the cultural perspective of pain management (Good, 2004; Good \& Moore, 1996; McCaffrey \& Locsin, 2006; Montes-Sandoval, 1999; Peterson \& Bredow, 2013; Appendix C).

\section{Study Conceptual Framework}

Demographic variables of age, gender, BMI, and veteran status were descriptively analyzed to ensure they were not significantly related to the study findings. Veteran status is important to include because it has been associated with chronic pain-related musculoskeletal injuries occurring because of muscle strain and combat injuries (Collins, Wilmoth, \& Schwartz, 2013; Koenig et al., 2014; Thompson, Chiasson, Loisel, Besemann, \& Pranger, 2009). Patient-specific characteristics, including eGFR, are 
evaluated in relation to the daily milligram morphine equivalent (MME), a nursecontrolled variable, to determine the relationship to pain variation (Figure 1). The daily MME day two post op is influenced by medical practice; however, nurses may assess the patient, evaluate choices for pain management, question specific medications, and consider alternatives (Berry \& Dahl, 2000a, 2000b; Curtiss, 2001). The Pasero OpioidInduced Sedation Scale (POSS) is reliable and produces valid data for measurement of sedation in patients receiving opioid analgesia (Jarzyna et al., 2011; Kobelt, Burke, \& Renker, 2014; Lim, Yobas, \& Chen, 2014; Nisbet \& Mooney-Cotter, 2009).

The average time between NPAs is a specific nursing care indicator and demonstrates a construct within the control of the nurse. Pain expectation management (acceptable level of pain) has been identified as one of the most important contributors to unmanaged pain (Carroll et al., 1999). Adjunctive therapy is a challenge to include in the model for this study due to missing values, therapy type, and dosage; however, exclusion of this variable may create a threat to internal validity. Differences in pain may exist between the total hip and the total knee arthroplasty groups when compared in relation to pain variability. This conceptual framework guides this research study (Ravitch \& Riggan, 2012). 


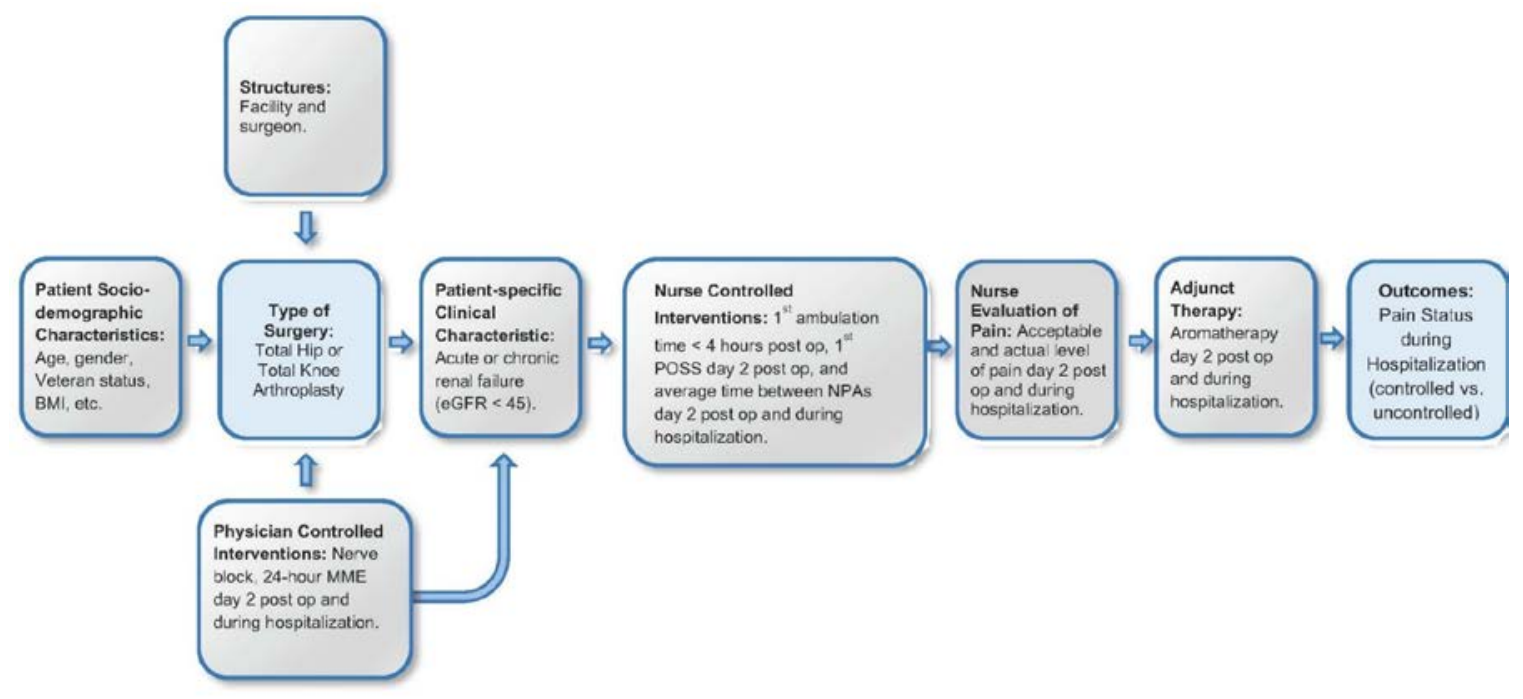

Figure 1. Study conceptual framework. Note: Adapted from pain theory paradigm (Good, 2004). eGFR=Estimated glomerular filtration rate; $M M E=$ Milligram morphine equivalent; NPAs=Nursing pain assessments; POSS=Pasero Opioid-Induced Sedation Scale; Post Op=Postoperative; Controlled pain status=Actual pain level reported by patients $\leq$ Patients' acceptable level pain. 


\section{CHAPTER II}

\section{LITERATURE REVIEW}

\section{A Revised Nursing Approach to Pain Management in an Era of Patient Harm}

In early 1991, the family of a nursing home resident was awarded 15 million

dollars in the case of State vs. McAfee because nurses refused to provide high doses of opioids to the resident due to concerns regarding addiction (Berry \& Dahl, 2000a).

During this time, physicians (i.e., surgeons), policymakers, professional nursing organizations, and many other healthcare organizations advocated for increased attention to pain management. Nurses were encouraged to advocate for pain medication orders and provide substantially increased doses of strong opioid medications for all types of pain (Devine et al., 1999; "RN news watch," 1999; Stratton Hill Jr, 1996).

In 2000, The Joint Commission (TJC; previously JCAHO) published new pain management standards that reframed pain management as a patient rights issue (Berry \& Dahl, 2000a, 2000b; Sandlin, 2000; Tormoehlen, Mowry, Bodle, \& Rusyniak, 2011; VandenBosch, 2002). In the decade following the release of the TJC pain standards, the United States health statistics listed medication poisoning as the leading cause of injury related death second only to automobile accidents. In 2016, the United States had $4.6 \%$ of the world population, yet consumed $80 \%$ of the opioid supply and $99 \%$ of the hydrocodone supply in the world (Pon, Awuah, Curi, Okyere, \& Stern, 2016). Research has identified a strong correlation between drug-poisoning mortality and geographical areas with high per capita sales of opioids (Okie, 2010). Since 2010, government policies, including Centers for Disease Control and Prevention (CDC) and Federal Drug Administration (FDA) guidelines, have begun to restrict the flow of legitimized opioid 
use (Cahana, Dansie, Theodore, Wilson, \& Turk, 2013; Dowell, Haegerich, \& Chou, 2016; U.S. Food and Drug Administration, 2016). However, patient reports of decreased availability of legally acquired opioids resulted in increased costs and sales of illegally acquired opioids, for example, heroin (Leavitt, 2011). Significant revisions to pain management practices are required to reduce unintended consequences of opioid consumption.

\section{Historical Perspective of Pain Practices and Policy}

In 2000, the new JC pain management standards required a nationwide campaign to revise pain management practices. As part of an interprofessional team, surgeons, pharmacists, and nurses were challenged with management of acute and chronic pain both in the inpatient and outpatient settings. Hospital nurses, the team members closest to the delivery of patient care, were strongly encouraged to take a proactive approach to ensure all patients were assessed and treated for pain prior to leaving their care (Berry \& Dahl, 2000a, 2000b; "New JCAHO standards," 2000; "RN news watch," 1999). However, in the decade following the release of the JC pain standards, deaths from unintentional opioid overdose closely paralleled the quantity of opioids ordered. The highest number of increased complications and accidental deaths were not in hospitalized patients but in young adults (ages 18 to 25), followed by adolescents (ages 12 to 17). Increased availability and inaccurate perception of increased safety of prescription medications is thought to contribute to opioid-related morbidity and mortality in these groups (Pon et al., 2016; Tormoehlen et al., 2011).

The reasons for the national opioid epidemic are complex. Government efforts to decrease opioid use have been counteracted by market demand and a legitimate need to 
control both acute and chronic pain. Unintended opioid addictions created personal difficulties for patients, including increased costs, increased time spent to acquire the medications, decreased attention, decreased energy, and adverse side effects for instance respiratory depression (Okie, 2010; Raffa \& Pergolizzi, 2014; Tormoehlen et al., 2011). The demand for opioids in the United States has grown faster than our ability to treat pain through safer and less addictive methods. Personal difficulties with opioid addiction have now resulted in mainstream difficulties; for example, difficulty treating surgical pain in hospitalized patients and overcrowded emergency departments and hospitals. In addition, demand for street drugs (e.g., heroin) increases when legitimized opioids are no longer available to patients (Cahana et al., 2013). Since 2010, a series of new practices, guidelines, and political mandates have been introduced to restrict the use of opioids (Cahana et al., 2013; Dowell, Haegerich, \& Chou, 2016; FDA, 2016; Franklin et al., 2015); however, failure to prevent unintended consequences of opioid use may not be avoided by the most well intended government interventions.

Nurses have an important role in addressing the opioid epidemic by ensuring opioid-sparing approaches to pain in the hospital setting. Empowerment of hospital nurses to provide opioid-sparing interventions in the acute care setting may allow many patients to completely avoid opioids while decreasing the need for opioids in others. Interprofessional collaboration between nurses, surgeons, and pharmacists supports individualized multimodal pain control measures for hospitalized patients. A multimodal approach increases the likelihood patients will avoid exposure to highly addictive opioids during brief hospitalizations (Fishman et al., 2013; McWilliam \& Botwinski, 2010). Strong state mandates are needed to support the healthcare team as they pursue a 
significant change to pain control practices by providing an opioid sparing, multimodal approach to pain control in the hospital setting.

\section{Alternatives to Pain Control Practices in an Era of Opioid Addiction}

Alternatives exist to address the opioid epidemic while ensuring proper management of pain. Mandatory opioid control is an alternative that may not be favored by many due to the unknown impact it will have across the United States. While voluntary controls may be preferable, they will likely require more time to produce change, and some evidence suggests this approach is ineffective.

\section{Voluntary vs. Mandatory Opioid Controls}

From 1999 to 2013 the number of opioid prescriptions demonstrated a positive relationship to opioid overdosing deaths (Pon et al., 2016). In March 2016, a CDC statement called for immediate action because "more than 40 Americans were dying each day” from prescription opioid overdoses (Dowell et al., 2016; Elkins, 2016; FDA, 2016). That same month, both the CDC and FDA published strong recommendations to decrease opioid prescriptions for chronic pain and place strong warnings on commonly prescribed opioids, for example, hydrocodone. These recommendations clearly state non-opioid treatment for chronic pain is preferred to opioid treatment, excluding pain from cancer, palliative, and end-of-life care.

While most of the United States has not enacted legislation to control the prescription of opioids, in response, many states are engaging in a voluntary stepwise approach to management of opioid use and abuse. Some states, for example California, have implemented prescription drug monitoring programs for prescription drug abuse. California’s program, called the Control Substance Utilization Review and Evaluation 
System (CURES), was offered as a tool to identify individuals engaging in "doctor shopping” and high-dose opioid use or abuse. Initially, CURES allowed providers and pharmacists to voluntarily subscribe; however, in the first 2 years, only $9.8 \%$ of eligible providers actually subscribed (Pon et al., 2016). As a result, the State of California mandated all eligible providers enroll by July 2016 to ensure access to all California providers (Bandyopadhyay et al., 2016). The effects of active use of CURES is yet to be determined.

Considering this evidence, it may be ineffective to apply voluntary measures to ameliorate one of the most serious human-made epidemics in American history. State and federal mandates for a comprehensive approach to reduce opioid use and abuse may be more a viable option. Washington State modeled a comprehensive political mandatedriven approach to pain management. The Washington State "Engrossed Substitute Health Capital 2876: Pain Management (ESHB 2876)” was passed by the legislature in 2010 to repeal permissive pain rules. The law provided opioid dosing criteria and guidance on seeking pain specialty consultation and tracking patients' clinical progress with a focus on successful pain management, functional status, and risk for adverse events related to opioid use, as well as tracking opioid abuse (Franklin et al., 2015). Implemented beginning in 2011, the new law required opioid prescribers in Washington State not to rely solely on patients' reports of pain, but to incorporate objective evidence by tracking the pain level and functional status of patients being treated for chronic noncancer pain. These prescribers were required to consult a pain specialist if a patient's daily dose rose above a specified threshold. Since enactment of this law, the age-adjusted 
rate per 100,000 deaths and hospitalizations has decreased, directly coinciding with decreased prescribing of opioids.

Historically, the health care system has been slow to implement comprehensive programs that address patient safety concerns. In 2012, the JC issued a Sentinel Event Alert warning providers increased opioid safety measures were needed to decrease respiratory depression and opioid-related deaths in the hospital setting (JC, 2012). This sentinel event alert had less impact on decreased opioid-related morbidity and mortality nationwide than Washington State's ESHB 2876. After the implementation of this law in 2011, Washington State demonstrated a reduction in opioid and heroin related adverse events for the first time in over a decade, while opioid related deaths continued to rise in the remainder of the United States (Cahana et al., 2013).

\section{Projected Outcome of Mandated Opioid Controls}

The release of the 2016 CDC Guidelines for prescribing opioids was accompanied by a warning that over 40 deaths occurred each day as a result of opioid associated events. Although it is not realistic to completely eliminate all of these deaths, the CDC estimates complete elimination would prevent 146,000 deaths over the next decade (Elkins, 2016). Washington State reported a 50\% reduction in opioid-related deaths after ESHB 2876 went into effect. A nationwide mandate mirroring this law may result in a projected 73,000 lives saved over the next decade, including heroin-related deaths (Cahana et al., 2013). 


\section{The Role of Nurses in Opioid Reduction}

As part of the interprofessional healthcare team, nurses play a key role in the reduction in use of opioids. Surgeons and pharmacists are responsible to order and dispense both opioid and non-opioid medications as appropriate, but bedside nursing judgment is a crucial for appropriate pain management. The Michigan Opioid Safety Score (MOSS) was designed to increase patient safety while empowering nurses with objective evidence of pain and opioid safety risks. Pain recognition and assessment by subjective report, as in "Pain as the fifth vital sign," are generally accepted as the initial step in treatment of pain, nonetheless objective risk assessment tools like the MOSS empower hospital nurses to ensure opioid-related patient safety. Multimodal analgesia incorporates non-opioid and adjuvant therapies and may be more reliably utilized as nurses are empowered to act on both subjective and objective assessments (Soto \& Yaldou, 2015).

\section{Nurse-Controlled Opioid Reductions vs. Historical Pain Management Practices}

Historically, nurses have been penalized for refusing to use large amounts of opioid medications (Berry \& Dahl, 2000a). Since the 2000 JC pain management standards were unveiled, nurses have been targeted for their ability to assess patients, evaluate choices for pain management, question use of specific medications, and consider alternatives (Berry \& Dahl, 2000a, 2000b; "New JCAHO standards," 2000; "RN news watch," 1999). It is argued, nurses must be empowered to provide leadership to redesign the delivery of pain management in patient care through multimodal analgesia and therapeutic patient education with proven efficacy in treatment of pain (Jarzyna et al., 2011; Vargas-Schaffer, \& Cogan, 2014). 
While inadequate pain control is unethical and the cost of unrelieved pain includes adverse physiological and psychological consequences, adverse events related to opioid use must be eliminated. Currently, nurses rely primarily on the subjective report of pain, but objective measures including sedation, breathing, and other risk factors must also be considered in the treatment of pain (Berry \& Dahl, 2000a; Soto \& Yaldou, 2015). Previously, nurses were encouraged to administer large amounts of opioids to patients with acute or chronic pain without fear of causing addictions during the hospital stay or as sequela to opioid therapy (Berry \& Dahl, 2000a, 2000b; Curtiss, 2001; "New JCAHO standards," 2000).

Current evidence strongly suggests patients with risk factors for addiction may become addicted with few opioid doses (Pon et al., 2016). Nursing guidelines and the World Health Organization (WHO) analgesic ladder now recommend oral non-opioid analgesics (NSAIDS) as the preferred approach to pain management. The WHO analgesic ladder recommends starting with NSAIDS with adjuvant therapy except for cancer-related pain and end-of-life care (Vargas-Schaffer, 2010; Vargas-Schaffer \& Cogan, 2014). Nurses are encouraged to act as strong advocates for pain management plans that incorporate opioid dose-sparing strategies by initiating treatment early in the course of patient care (Jarzyna et al., 2011).

Confronting trade-offs. Decreasing opioid availability and use through political mandates, for example, Washington State Legislature’s ESHB 2876 would likely have immediate and profound effects in pain management, while substantially decreasing unintended consequences of opioid-related injury and death. Hospital nursing care sets the trajectory for patients managing their pain at home; consequently, hospital nurses 
must be empowered to practice using a multimodal approach backed by strong state mandates to ensure interprofessional collaboration between surgeons, pharmacists, and nurses. This interprofessional team has previously yielded to demands for prescribing and administering high-dose opioids to opioid-tolerant patients, who in turn have a false sense of safety because the opioids were prescribed. Increased availability of prescription opioids provided individuals under 25 years old access (via home medication cabinets) to potent opioid based medications and exacerbated the opioid epidemic in the United States (Cahana et al., 2013; Franklin et al., 2015).

Heroin abuse. The increase of opioid prescriptions during the 1990s brought addictive medications to areas that had no distribution network for addictive drugs of abuse, for example, heroin (Okie, 2010), which continues to be a public health concern (Jones, 2013). Nationally, heroin use has increased, representing a transition from prescription opioids to heroin in some patients (Cahana et al., 2013; Franklin et al., 2015; Jones, 2013; Okie, 2010). In the State of Washington, public officials collaborated to track opioid-related and heroin-related deaths and hospitalizations along with high-dose prescriptions and evidence of adolescent opioid abuse (Franklin et al., 2015). Although tighter controls have been implemented, since 2011 overdoses and deaths remain higher for prescribed opioids than heroin. However, in a study of Washington State 10th graders who usually obtained opioids from a home medicine cabinet, nonmedical use of opioids declined from 10\% in 2006 to 6\% in 2012 (Franklin et al., 2015).

Anecdotal stories of uncontrolled pain. Anecdotal stories with patient accounts of excruciating, untreated pain have continued to permeate both peer-reviewed literature and the news (Andrews, 2011; Leavitt, 2011; Sandlin, 2000). Some authors have 
suggested all nursing and medical students undergo a painful procedure before being allowed to graduate in order to have true empathy for their patients (Sandlin, 2000). Although anecdotal stories are compelling, pain management guidelines that balance patient safety concerns with pain management must be based on scientific evidence and best practices. Adjuvant therapy, non-opioids, and other medications without addictive properties are a viable option for pain control (Jarzyna et al., 2011).

Cancer and end-of-life pain. Current guidelines and mandates specifically exclude cancer-related and end-of-life pain from limitations on the amount or frequency of opioid dosing required to treat the pain (Cahana et al., 2013; Jarzyna et al., 2011).

Uncontrolled chronic pain. Both legal mandates and voluntary efforts to control opioids have received criticism due to specific instances of failure to adequately treat acute, chronic, or acute on chronic pain. Often patients with chronic pain using greater than 120 mg per day of opioids still report uncontrolled pain; however, as the dose is increased these patients have not realized a substantial improvement in function, while complications increase exponentially (Cahana et al., 2013). These opioid-tolerant patients continue to demand opioid medications often due to the addictive properties, confirming their pain is not controlled while on high doses of opioids. The new pain guidelines and legal mandates are intended to decrease opioid tolerance by creating a stepped approach to pain management to ensure opioid tolerant patients receive opioid tapering combined with alternate medication regimens to successfully treat pain, while increasing functional abilities (Cahana et al., 2013; Elkins, 2016; Franklin et al., 2015; Jarzyna et al., 2011; Neven, Sabel, Howell, \& Carlisle, 2012). 
Surgical pain. The consequences of serious opioid-related complications including unintended addiction and respiratory depression are concerns for patients with acute surgical pain and acute surgical pain underlying chronic pain. Although opioid use is appropriate in this setting, it is no longer appropriate as an exclusive approach to pain management (Jarzyna et al., 2011). Patient-specific factors must be assessed to determine the benefits and risks of opioid-related adverse events.

Nurses play an important role in assessing risk factors while developing a plan of care to intervene and prevent unintended consequences of opioid sedation (Jarzyna et al., 2011; Soto \& Yaldou, 2015). Implementation of a multimodal approach is now a Class-1 recommendation (strong evidence) for nurses by the American Society for Pain Management and the American Pain Society Guidelines on the Management of Postoperative Pain (Chou et al., 2016; Jarzyna et al., 2011). Multimodal analgesic therapy is now the first line approach for pain management. Multimodal therapy combines nonopioids with opioids and considers the potentiating effects of other medications that produce sedation (Jarzyna et al., 2011). The multimodal approach to pain management is based on WHO analgesic ladder that uses a stepwise approach to treat surgical pain (Raffa \& Pergolizzi, 2014; G. Vargas-Schaffer, 2010). Therapeutic patient education is central to multimodal pain management. Nurses provide education to assist patients and their families when managing treatments and avoiding preventable complications while maintaining or improving quality of life (Vargas-Schaffer \& Cogan, 2014).

\section{Improved Nursing Outcomes}

The Institutes of Medicine report, The Future of Nursing: Leading Change, Advancing Health (2011), asserts patient safety and quality improvement efforts are 
dependent on a strong nursing voice. In 2014, The President's Council proposed systems engineering to inform health care by design, thereby reducing waste while increasing healthcare reliability (Cassel \& Saunders, 2014). Nurses are the largest segment of the healthcare workforce and practice in a variety of settings. The majority of all US nurses work within the hospital setting, where community health concerns, policy, and healthcare mandates interconnect with the patient care nurses provide (Allen, 2004, 2014; Drake, Luna, Georges, \& Steege, 2012). Systems engineering informs all nursing roles, including clinical practice, and supports effective complex decision-making ability and problem-solving strategies (Cassel \& Saunders, 2014). In hospitals, nursing staff practice according to standard operating procedures, policies, and protocols, but it is easy to find nurses doing the same work in a variety of ways, often creating waste manifested as patient harm (Barnas, 2011; Ching, Williams, Idemoto, \& Blackmore, 2014; Graban, 2011; Mannon, 2014). Decreasing healthcare waste through standardized work provides opportunities to decrease patient harm (Drake et al., 2012; Graban, 2011; Toussaint \& Berry, 2013) and achieve optimal patient outcomes, which are inseparable from the work of the nurse (Drake et al., 2012).

Although it is not possible to standardize every aspect of nursing care, the target state of standardized work in nursing is achievable (Ben-Tovim et al., 2007; Graban, 2011; Kalisch, 2015; Mannon, 2014). The concept of standardized work provides a framework to assist in the proactive design of nursing work. Standardized work is effective when implemented as an iterative dynamic process to amplify the voice of the patient and clinical nurses to develop a standardized approach to complex clinical problems including pain management (Graban, 2011). 
Variation in nursing practices for pain management must be evaluated to facilitate the development of informed standardized nursing work (Graban, 2011). Nurses support medical management through administration of potent opioid therapy, but increased focus on implementation of adjunctive therapies for pain management is needed (Jarzyna et al., 2011). Pain management that includes adjunct therapy including aromatherapy, comfort massage, relaxation, and music are examples of key nursing care. Providing adjunct therapy enables nurses to contribute to the balance between analgesia and side effects (Peterson \& Bredow, 2013).

\section{Nurse-Controlled Work Design}

Nurses are well-positioned to lead opioid reduction efforts using proactive approaches (e.g. standardized work), informed by systems engineering, to inform nursing practice and improve pain management. However, in order to design a standardized nursing approach to pain management for hospital nurses, nursing research must identify the significant variables that affect pain control. Standardized work is designed to include key elements or variables found to be predictive for uncontrolled pain in hospitalized patients and create a dynamic process improvement model for effective treatment of complex pain management. Hospital nurses can contribute to decreasing unintended opioid dependence by modeling a standardized approach to multimodal therapy with decreased opioid use in the hospital setting.

\section{Introduction to the Concept of Standardized Work}

The national movement to improve quality and safety began in earnest in the year 2000, when continual pressure on healthcare budgets, increasing health demands, and the report, “To Err Is Human,” alarmed both healthcare providers and patients (Kohn, 
Corrigan, \& Donaldson, 2000). In 2013, Chassin and Loeb emphasized the need for the transition to highly reliable organization (HRO) and stated high-reliability science has allowed other industries, including aviation and nuclear power, to operate at much higher safety levels than healthcare. Health delivery systems have turned to other industries for methodology as they seek a transition to HRO. The HRO quality improvement philosophy incorporates a set of principles, synthesized by the Toyota Motor Company, designated a Lean philosophy (Toussaint \& Berry, 2013). Robust process improvement utilizing the Lean, Six Sigma, and change management tools were seen as methodology to enhance the healthcare industry's ability to provide safe patient care (Chassin \& Loeb, 2013). Standardized work is a central principle of the Lean philosophy (Toussaint \& Berry, 2013).

\section{Standardized Work Concept Background}

Standardized work incorporates many components from industrial engineering and management. These components are based in research and quality improvement methodology. Standardized work must include scientific evidence, caregiver consensus, change management principles to create an optimized process that is reviewed periodically to incorporate new knowledge and address process failures (Mannon, 2014; S. J. Spear, 1999; Toussaint \& Berry, 2013; Womack \& Jones, 2010). The concepts Standardized Work and Standard Work are used synonymously throughout the literature. Standardized work is a verb or a state of the environment created by the scientific management method applied to daily work (Gilbreth, 1914; Taylor, 1914; Womack \& Jones, 2010). The scientific management method requires definition of a measurable hypothesis about how a process may be improved. The hypothesis must then be tested. 
When improvement occurs and desired outcomes are realized, this improved process becomes standardized work until new knowledge allows for further improvement (Toussaint \& Berry, 2013). In the standardized work environment, the definition of excellence continues to change due to a culture of continuous quality improvement. Although standardized work implies high quality, it is work that produces optimal outcomes with specified content, sequence, and timing to ensure results are reproducible (Spear, 1999). Standardized work also contains a dynamic attribute that requires continuous and immediate correction of process failures at the point closest to the failure. The Toyota Production System outlines the four rules for Standardized work that require continual analysis, research for new knowledge, and active listening between all levels of the organization to sustain the state of Standardized work (Spear \& Bowen, 1999).

\section{Aim(s) of Analysis}

A concept analysis was conducted to define and analyze standardized work (verb) as it relates to nursing practice and health care, while differentiating between standard work (static noun) and standard work (verb). Standardized work is effective when implemented as an iterative dynamic process to amplify the voice of the patient and clinical nurses to develop a standardized approach to the complex clinical process of pain management. Variation in nursing practices for pain management must be evaluated to facilitate the development of informed standardized nursing work (Graban, 2011).

\section{Concept Definition and Uses}

The word standard is defined by Merriam-Webster as both a noun and an adjective with multiple definitions. For the purpose of this analysis, a standard is "an ideal or rule for comparison, regularly and widely used in the practice or the profession, 
and widely known and accepted to be of good and permanent value” (2015). The word work is also both a noun and a verb with multiple definitions. For the purposes of this concept analysis, work is "an activity in which one exerts strength to do or perform something, sustained physical or mental effort to overcome obstacles and achieve an objective or result including labor, task, or duty” (Merriam-Webster, 2015).

In 1907, Frederick Taylor, known as the "Father of Scientific Management," coined the term one best way. As part of his management theory, his obsession with time incentivized him to develop the stopwatch resulting in being either loved or hated, which translate to many efficiency experts today. Taylor formed a close friendship with the husband and wife team, Frank and Lillian Gilbreth, whose team dynamics are still influential today. The standard work concept appears in Lillian Gilbreth’s PhD dissertation, “The Psychology of Management,” in which she creates the term standardization of work (Gilbreth, 1914). Lillian and Frank Gilbreth were industrial engineers who believed in "the urgent and driving need for efficiency." Their work was to decrease the time required for both industrial and building construction tasks (Witzel \& Warner, 2013). By studying work processes using light and photography, the Gilbreths found many steps taken by workers were unnecessary, resulting in increased worker stress and decreased productivity. Lillian applied these scientific process improvement methods to handle the Victorian woman's housework. This focus allowed her to take her place as one of the first working female industrial engineers.

In 1913, Henry Ford was the first to completely incorporate the concept of standardized work to his assembly line into what he called "flow production.” (Witzel, \& Warner, 2013). Later, in the 1930s, Kiichiro Toyoda and others at Toyota investigated 
Ford's process flow and found with a few innovations they could create new thinking that would allow them to provide better process flow and more variety of vehicles. This was the genesis of the Toyota Production System, now the basis for Lean thinking, which was used to develop the state of standardized work as the antidote to manufacturing, service industry, and healthcare waste (Spear, 1999; Thompson, Wolf, \& Spear, 2003; Womack, 2005, 2006; Womack \& Jones, 1996; Womack, Jones, \& Cahoon, 2006).

Healthcare has frequently borrowed engineering principles from manufacturing and service industries to improve healthcare quality (Sloan et al., 2014). Standardized work is the target state in which nurses and the healthcare industry continually strive to eliminate waste (Toussaint \& Berry, 2013). There are specific attributes that must be present for a true state of standardized work to occur (Spear, 1999).

\section{Defining Attributes}

Avant and Walker (2011) describe the defining attributes of a concept as the most frequently occurring attributes that may be associated with that concept (cited in Molon, 2014). The defining attributes or attributes of standardized work include specified content, specified sequence, specified timing, specified outcome, and dynamic (Spear \& Bowen, 1999; Thompson et al., 2003).

Specified content. Once a problem is identified as a concern to nursing or healthcare, a team must be selected to research content required to satisfactorily address the identified problem. Specified content may only be determined after the research has been completed. The content of standardized work must be the latest evidence-based practice recommendations when the content is developed. In addition to a review of the relevant literature, additional insight into best practices is gained by networking to 
identify community practice; appreciation of the laws and standards governing the identified problem must be included in the content. Once the content is specified it must then be reduced to the purest form. Standardized work is the most succinct content possible to achieve the intended outcome. Toyota's first rule states all work must be highly specified as to content (Kim at el., 2009; Mannon, 2014; Spear \& Bowen, 1999; Spear, 1999; Womack \& Jones, 1996).

Specified sequence. The Lean concepts also require all work to be highly specified as to sequence. An example of critical sequencing in nursing is the barcoding process in medication administration (Koppel, Wetterneck, Telles, \& Karsh, 2008; Spear \& Schmidhofer, 2005). Workarounds for barcoding have been a challenge to all healthcare organizations (Spear \& Schmidhofer, 2005). The reasons for nursing workarounds for barcoding during medication administration are numerous and often complex. For example, when a computer on wheels is not available for the nurse to take to the bedside for timely medication administration, a workaround will often occur (Koppel et al., 2008). Since nurses are under significant pressure to administer medication within a specified window they may print the patient medication lists, obtain the medications, and then scan the barcode on the empty packages after the medications have been administered. Although the nurse may be careful to follow the "rights of medication administration," an important safety check is removed by scanning the medications after they have been administered. The sequence of events is critical. In the target state of standardized work process failures, for example, the computer on wheels that is not available is corrected in real time through the dynamic communication attribute of the standard work state (Spear \& Bowen, 1999; Toussaint \& Berry, 2013; 
Womack \& Jones, 1996). Each of these attributes (i.e., specific sequence) is distinct but closely linked to all other aspects of the concept.

Specified timing. Specified timing is defined as the ideal rate or time each step in the process must be completed to achieve the desired outcome (Cveykus \& Carter, 2006). In Lean terminology, this ideal time is called takt time, a musical term taken from the German language meaning "rhythm or pace” (Womack \& Jones, 2010). In a setting that reached the ideal state of standardized work it is operating within the specified timing. Every task, work step, cycle, or distance has an appropriate time window. For example, most medication administration must occur within 30 minutes of the scheduled dose time (Eisenhauer, Hurley, \& Dolan, 2007); however venous-thromboembolism prophylaxis has been shown to be effective if implemented within the first two calendar days of admission (Labarere et al., 2004). Specifications for takt time will change dependent on the selected work process.

Specified outcome. A specified outcome serves as an ongoing assessment of the effectiveness of all individual attributes in the concept of standardized work. At Toyota, specified outcomes are measured in manufacturing terms of output. For example the output must be defect free, meaning it contains the features and performance the customer expects (Spear \& Bowen, 1999). Customer satisfaction in manufacturing may be compared to patient satisfaction in healthcare. Customer and patient satisfaction have become key metrics for each industry’s outcome measurement. Healthcare, like manufacturing, has numerous essential and specific outcomes. Healthcare and nursing specific outcomes include patient safety, decreased costs, increased efficiency, healthcare worker safety, increased reimbursement, TJC core measure compliance, and many more 
target goals (Kim et al., 2009; Mannon, 2014; Spear \& Bowen, 1999; Womack \& Jones, 1996). When the specified outcomes are not achieved, the other attributes of standardized work must be incrementally adjusted until the ideal state of standardized work is realized. The work may not be considered to be in a standardized state until the desired outcome is fully realized (Rother, 2010).

Dynamic. The Japanese describe the dynamic attribute of standardized work as kaizen, where kai means “continuous” and zen means “improvement.” This term is usually applied to an event that begins the change process but after the kaizen event; process improvement is understood to be ongoing (Cveykus \& Carter, 2006). The Lean tools of Toyota are not considered a permanent solution. Each tool is only a response to a particular problem until a better tool is found or changes to conditions result in a new understanding for the most recent embodiment of the standardized work (Spear \& Bowen, 1999). The dynamic component of standardized work was first described as taking “initiative” by Frederick Taylor in 1914. He stated each man took the initiative to find the best way to do his work, however the younger generation would inevitably build on that knowledge and find a better way (Taylor, 1914). Lillian Gilbreth went on to describe scientific management as a process in which standardization always applies as an exercise of ingenuity in making improvements after learning the standardized practice (1914). Almost 100 years later, in 2013, Toussaint described the lean quality improvement philosophy as an attitude of continuous improvement. While the standard describes how a process should operate, standardized work or standard work means the process is operating as specified in the standard. Standardized work is a condition, a continually changing state. A continual reassessment must be made to determine if the 
standardized condition exists or not. This is the process of establishing a target condition (Rother, 2010). Merriam-Webster describes a process as "a series of actions that produce something or that lead to a particular result and dynamic is defined as "always active or changing” (2015). Solutions developed for a specific problem at a specific time may not apply at a later time. It is like thinking ahead many years and projecting things will be exactly the same. This static process is not realistic. In order to remain in a standardized state, it is important to make incremental changes responding to actual conditions in the workplace (Rother, 2010). Standardized work is a dynamic state because it must change as situations change and new knowledge is introduced.

\section{Constructed Cases}

Walker and Avant (2011) recommend the use of constructed cases to illustrate a concept by use of the antecedents, attributes, and consequences within a case study. The model case contains all of the attributes, while a contrary case contains none of the attributes and a borderline case contains many of the attributes but not all. A contrary case is developed to demonstrate what is not the concept of standardized work (Walker \& Avant, 2011).

Model case. The orthopedic unit cares for patients with high risk for venous thromboembolisms. The hospital unit was at risk for preventable harm waste. In response to The Joint Commission's Core Measure (VTE) prophylaxis requirement, the leadership team developed a dynamic process with evidence-based content. An algorithm describing the sequence was adopted into nursing practice with clearly defined timing for the specified VTE prophylaxis to occur. The patient outcomes demonstrated there were no events of venous thromboembolisms after the implementation of this process. The 
nursing outcomes demonstrated no waste of mental or physical energy due to the clear and succinct approach to VTE prophylaxis. The nurses communicated all process failures as they occurred and the leadership made immediate corrections by use of simple twoway communication pathway. During daily rounds, the Clinical Nurse Specialist team observed nursing practice and found the VTE prophylaxis standardized work state was still present because continual process improvements were made to achieve the target goals and operate as specified in the current content, sequence, timing, and achieve optimal outcomes demonstrated by the absence of venous-thromboembolisms in their patients and the least waste of the nurse's mental and physical activity (Kwan, Daniels, Ryan, \& Fields, 2015; see Figure 1).

Contrary case. The orthopedic unit cares for patients who are high risk for venous thromboembolisms. In response to The Joint Commission's Core Measure (VTE) prophylaxis requirement, the unit's leadership team rolled out education and required the nurses to sign they received the Standard Work tool and would ensure each patient received VTE prophylaxis during the first two days of the patient's admission. The nurses were disciplined for non-compliance. Each nurse on the orthopedic unit had a slightly different understanding of the requirement's content, sequence of treatment, and timing. Some nurses treated their patients within 24 hours, others waited 48 hours or more. During their daily rounds, the Clinical Nurse Specialist Team found the nursing processes for VTE prophylaxis varied greatly throughout the unit. Although there was a decrease in actual venous thromboembolism, incidences of actual VTE remained. The Clinical Nurse Specialist team concluded standardized work did not exist on this unit because there was not a specified sequence, timing, outcomes, or dynamic attributes present. 


\section{Antecedents}

According to Walker and Avant (2011) antecedents are events that immediately precede the concept. The literature identifies many conditions that lead up to the need for standardized work. Management, industrial engineering, and healthcare literature have identified waste as the primary antecedent to standardized work. In 1907 Lillian Gilbreth identified the need for scientific management to include the standardization of all work to decrease the waste. She theorized standardization increased workers' productivity by functionalizing their work to decrease mental and physical waste, thereby enhancing their individual abilities (Gilbreth, 1914). The term muri, Japanese for the most serious type of waste, was the Toyota Manufacturing Industry’s primary antecedent to standardized work (Rother, 2010).

In healthcare and nursing, the primary antecedent to the concept of standardized work is also waste. This waste may include healthcare provider or nursing resources including, time, mental attention, physical strain, over-time, increase costs, stagnation, and ultimately organizational ineffectiveness or waste. The three primary forms of provider-related healthcare waste are process inefficiency, overuse, and preventable harm. It is estimated $40 \%$ of healthcare spending is waste (Swensen, Dilling, McCarty, Bolton, \& Harper, 2013). This waste increases risk for patient harm by errors of omission or commission, healthcare worker or nursing over-time, and healthcare costs related to inefficiency and waste (Kalisch, 2015). This creates a moral and financial imperative to decrease waste.

Process inefficiency. Process inefficiency waste results in patient dissatisfaction and harm. The streamlining of processes and elimination of variation results in financial 
gain and increased patient satisfaction. Process inefficiency may include more steps to a process than necessary or greater distances and increased worker movements. Studies of the motions of workers demonstrate better sequencing and workstation arrangements result in less strain to the workers and greater productivity (Gilbreth, 1911). Process efficiency is now a key focus for healthcare organizations. Interdisciplinary healthcare teams have realized cost savings and error reduction as a result of creating a standard approach to work (Mannon, 2014; Swensen et al., 2013; Toussaint \& Berry, 2013).

Overuse. Overuse waste is a substantial problem in healthcare. The direct costs include unwarranted interventions, unnecessary exposure to radiation, and the errors that occur as a result. Patient time off work for testing, increased morbidity, and mortality are overuse costs that are difficult to accurately measure. Incidental findings from unwarranted tests also increase the costs to the healthcare system. Appropriate use of nursing and medical resources is both a financial and ethical imperative. Reduction of overuse waste is now encouraged by both insurers and fee for service reimbursements (Swensen et al., 2013).

\section{Consequences}

According to Walker and Avant (2011) consequences are events that occur as a result of the concept. The consequences of standardized work are clearly described in management, industrial engineering, and healthcare literature. While many processes may produce some degree of quality improvement, it is unlikely these results will be sustained without the implementation of standardized work (Rother, 2010). There are both negative and positive consequences to standardized work. The positive consequences far outweigh the negative consequences. Negative consequences include costs for new employees, 
construction costs to build greater, education and training costs, and additional wages for time spent during the process change; however, a detailed analysis of the cost versus waste demonstrates standardized work is beneficial. A business case for healthcare quality improvement describes how standardized work allows healthcare professionals to meet their ethical and fiduciary responsibility while decreasing variation waste and defects that cause harm and costs tremendous amounts of money. An estimated $40 \%$ of all healthcare dollars go to waste (Swensen et al., 2013; Appendix A).

\section{Empirical Referents}

The empirical referents for standardized work are found in observation for the presence of each of the defining attributes and tracking of the outcome measures or matrices for the specific process to ensure actual improvement.

Operational definition. The operational definition for standardized work (verb) is a dynamic process that is actually operating as specified in regard to content, sequence, timing, and outcome to decrease waste of time and resources. This concept use is in contrast to Standard Work (adjective - noun) demonstrated in Taylor’s work, “One Best Way” (Witzel \& Warner, 2013; Appendix A).

\section{Use of Standardized Work Concept for Pain}

Standardized work is the core principle of the Lean philosophy (Barnas, 2011). The operational definition for standardized work (verb) is a dynamic process that is actually operating as specified in regard to content, sequence, timing, and outcome to eliminate waste (Spear, 1999; Toussaint \& Berry, 2013). Standardized work generates optimized processes in healthcare and nursing practice. Although each problem presents different challenges, the attributes of standardized work provide a model for assessment 
of the target state. Often, nurses and other healthcare workers will address some of the attributes in standardized work, resulting in some improvement to the outcome. Other times, well researched processes are put into place with minimal or no outcome improvement (Rother, 2010). Outcomes are dependent on correct identification of the unique problems occurring in the healthcare setting. The problem of uncontrolled pain in the orthopedic surgical patient population may benefit from a standardized nursing process for pain control.

\section{Concept Operationalization of Controlled Pain}

Patients' experiences of pain are subjective and multifaceted. It is currently not possible to objectively measure pain intensity, supporting the widespread belief the patient's report of pain is the most reliable measure (McCaffery \& Pasero, 1997; Pasero, Quinlan-Colwell, Rae, Broglio, \& Drew, 2016). Pain in the hospitalized patient requires the nurse to make a judgment regarding pain control. In other settings, the patient is responsible for self-care, making independent decisions regarding pain control. The nursing care goal for the hospitalized patient is to provide safe and effective pain management resulting in controlled pain. Controlled pain is typically measured by selfreport and the use of pain intensity rating scales to determine the level of pain and if pain is either controlled or uncontrolled (Pasero et al., 2016). The purpose of this analysis is to operationalize the theoretical concept of controlled pain by the nurse in the hospital setting used for the purpose of quantitative measurement in research (Waltz, Strickland, \& Lenz, 2017).

\section{Historical Perspective of Pain}

The historical concept of pain comes from the Latin word poena meaning 
"punishment”; however, the contemporary conceptualization of pain has evolved into two philosophic approaches defining pain for nurses' clinical decision making process. The first approach, the externalist perceptual philosophy of pain, regards pain to be a perceptual experience that can be "misperceived" by the patient having the experience. The second approach, the non-representational view, regards pain as a holistic experience that may only be measured as subjective experience as conceptualized by each individual patient (Pesut \& McDonald, 2007). Control is defined as the restriction of an activity, tendency, or phenomenon (Merriam-Webster, 2018). The theoretical definition of controlled pain is the nurse's successful restriction of the patient's pain measured by selfreport in the hospital setting through various nursing interventions. The concept of controlled pain is applied by nurses through a general understanding of effective nursing practice ensuring patient comfort in caregiving situations (Pesut \& McDonald, 2007). McCaffrey (1972) inspired a revolution in pain management by giving credibility to the patient experience of pain by defining pain as "whatever experience person says it is" (Pesut \& McDonald, 2007, pp. 257). Nurses learn to discriminate between various components of the pain experience; however, lack of time to conduct, document, and repeat a comprehensive assessment necessitates the use of simple assessment instruments to determine the patient's perspective of their own pain experience (American Society for Pain Management Nursing [ASPMN], 2018).

Mental, emotional, and social consequences may also be sequela of uncontrolled pain. Specifically, these consequences include depression anxiety, impaired cognition, declining socialization, and isolation from friends and family members. The concept of 
controlled pain may take on the various meanings based on the patient's experience of discomfort whether physical, mental, emotional, or social.

Pain management goals are negotiated between the patient and the nurse. The pain management goal is the perceived amount of pain the patient can tolerate without significantly affecting the patient's ability to function in an important way, including walking with a steady gait, sleeping, and eating. Although pain is no longer considered the fifth vital sign, frequent pain assessments are often necessary in order to assist patients in reaching their pain management goals (Pain Management and Schedule II Drug Prescriptions Assembly Bill 2017 (CA) No. 1048).

Instruments that are easy-to-use, reliable and generate valid data are all essential aspects of a pain rating scale needed for widespread use and frequent reassessments of patient's pain (Hawker, Mian, Kendzerska, \& French, 2011). An operational definition specific to the idea of controlled pain is needed to move important measurement work forward.

\section{Theoretical and Operational Definitions}

Theoretical definition. Controlled pain is defined in terms of human subjectivity for the realities of clinical decision-making to optimize patients comfort and ability to function. The actual theoretical definition put forth in this study is "is the subjective report of pain that is usually at or below the acceptable level of pain.”

Operational definition. The operational definition is "the subjective report of pain as measured by (1) a clinically appropriate pain scale and then (2) compared to the patient's pain goals negotiated between the patient and the nurse as the acceptable level of pain.” 


\section{Variables for Controlled Pain}

Variables emanating from the theoretical definition. The theoretic definition

presented above requires a comprehensive understanding of the patient's pain experience (Matthews \& Malcolm, 2007) including empathetic approach to ameliorating the patient's experience of pain with refined control strategies. Physiologic and sensory variables may include location, intensity, duration, quality, aggravating and relieving factors, associated factors (e. g., nausea, constipation, difficulty sleeping, or itching) and possibly many more. Other variables may include emotion, mental state, cognition, sociocultural and aspects of the environmental variables (ASPMN, 2018).

Measurable items emanating from the operational definition. The operational definition of controlled pain is (1) subjective report of actual pain as measured by a clinically appropriate pain scale, (2) compared to the patient's pain goals negotiated between the patient and the nurse as the acceptable level of pain (Pasero et al., 2016). Controlled pain is the subjective report of pain as measured by a clinically appropriate scale usually at or below the acceptable level of pain (Buss \& Melderis, 2002).

Subjective report of actual pain. Subjective measures collected by a numeric rating scale that uses numbers, usually 1 to 10 , to describe the extremes of the patient's report of actual pain, presented in a rank order of severity is the first step (Roden \& Sturman, 2009). The most commonly used scale for verbal and literate patients is the Numeric Rating Scale (NRS). The NRS is a unidimensional, easy-to-use, scale containing whole numbers, usually from 0 to 10 , to describe the intensity of the patient's pain. Commonly, a visual representation along the horizontal or vertical line is anchored at the lowest and highest extremes by a descriptive phrase. Nurses often vary these anchors 
between 0 (no pain at all, on the low extreme) to 10 (the worst pain imaginable or as bad as has ever been felt, on the high extreme). Different answers may be given by the same patient based on previous experiences resulting in the lack of stability, a form of reliability (Pasero et al., 2016). The NRS may not be used as ratio level data because the difference between a score of 1 and 2 may not be the same as the difference between a score of 8 and 9, or the NRS score of 4 may not be twice as much as 2. Patients may not clearly use or understand the NRS as a continuous score, but rather a categorical measure. Acceptable pain is the level of pain measured on an NRS the patient can tolerate and still function in an important way (Buss \& Melderis, 2002; Hayes \& Gordon, 2015). The NRS is a unidimensional scale that captures only the subjective pain intensity school undervaluing the complex nature of the patient's pain experience. The NRS is an intensity rating scale, but the act of exclusively rating the intensity requires the patient to reduce all aspects of their pain experience into a single number. Although the NRS is not intended to rate other aspects of the pain experience (e.g., anxiety), nurses often report treating pain when anxiety is the problem due to patients' misunderstanding of the experience, which may represent a dichotomy in philosophical viewpoints accepting the externalist perceptual philosophy of pain (Pesut \& McDonald, 2007).

As the second step, the actual pain score would be compared to acceptable level of pain, which is the patient's goal, in order to determine if pain is controlled or uncontrolled. Controlled pain as a score at or below the acceptable level of pain as measured by the NRS would be a starting point for measuring controlled pain. As stated above, there are many variables identified in the theoretical definition that would need to be eventually operationalized in order to comprehensively measure controlled pain. This 
second step ultimately requires the generation of dichotomous level data (e.g., controlled vs. uncontrolled pain).

\section{Electronic Health Record Data}

Pain status is recorded by nurses in the electronic health record (EHR) as part of the record of care provided. EHRs provide opportunity to enhance care through detailed tracking and may also be useful for clinical research. "Pain Status" is a product of two common data fields: actual pain on a scale of 1 to 10 and acceptable level of pain on a scale of 1 to 10 , with zero being the absence of pain. The lack of standardized data fields to include clinically relevant data is one of the many challenges of using the EHR for clinical research (Roth, Lim, Pevnick, Asch, \& McGlynn, 2009). Busy nursing workloads and other distractions may contribute to errors in nursing data recording. Data reliability and validity of EHR data for use in clinical trials has been questioned (Roth et al., 2009); however, data collected by the electronic case reports including the American Heart Association Get With the Guidelines (AHA GWTG) have also questioned the need for duplicate data collection because the EHR houses vast amounts of medical data to support longitudinal and observational studies. Although EHRs were originally designed as a billing system and not designed to inform clinical workflows, new national legislation requires an optimized EHR to improve clinical care and enhance relevance to clinical research (Cowie et al., 2017; Roth et al., 2009; Thoroddsen, Sigurjónsdóttir, Ehnfors, \& Ehrenberg, 2013). Increased clinical research using the EHR will provide evidence of the payoff of extra clinical time focused on ensuring EHR data reliability and validity. Clinicians and researchers must be committed to ensuring the integrity of the data and advancing validation methodology and flexible in adjusting their workflow to 
allow optimization of clinical practice and research. Accurate EHR data collected by clinicians is required as a reliable and valid source of information for clinical decisionmaking, quality improvements, research and policy. Improved nursing outcomes are informed by research using EHR data that accurately corresponds to the reality of the clinical status of the patient (Cowie et al., 2017; Thoroddsen et al., 2013).

\section{Summary}

Patients' experiences of pain are subjective and multifaceted in nature. It is currently not possible to objectively measure pain intensity supporting the widespread belief the patient's report of pain is the most reliable measure (McCaffery \& Pasero, 1997; Pasero et al., 2016). The conceptualization of pain has evolved through two philosophic approaches defining pain for nurses' clinical decision making. The contemporary and widely accepted approach, the non-representational view, regards pain as a holistic experience that may only be measured as subjective experience as conceptualized by each individual patient. The concept of controlled pain is applied by nurses as a general understanding of successful nursing practice, ensuring patient comfort in caregiving situations (Pesut \& McDonald, 2007). The theoretical concept of controlled pain is defined in terms of human subjectivity for the realities of clinical decision-making to optimize patients' comfort and ability to function. The operational definition is the subjective report of actual pain as measured by a clinically appropriate pain scale compared to the patient's pain goals negotiated between the patient and the nurse as the acceptable level of pain.

A portion of controlled pain may be measured by pain intensity rating scales (Pasero et al., 2016). Ultimately, pain is either controlled or uncontrolled. Although the 
patient's experiences of pain are subjective and multifaceted, it is currently not possible to fully measure controlled pain. This supports the widespread belief the patient's report of pain is the most reliable measure (McCaffery \& Pasero, 1997; Pasero et al., 2016). Pain in the hospitalized patient requires the nurse to make a judgment regarding pain control. It is a widely-held belief that nursing care for the hospitalized patient that provides safe and effective pain management results in controlled pain. Operationalization of the theoretical concept of controlled pain by the nurse in the hospital setting facilitates conceptualization of the variables for the purpose of quantitative measurement in research (Waltz, 2017). As the volume and accuracy of EHR data has increased, this existing data source has evolved into a valuable clinical research resource. Improved nursing outcomes are informed by research using EHR data collected from standardized fields are assumed to accurately correspond to the reality of the clinical status of the patient (Cowie et al., 2017; Thoroddsen et al., 2013). 


\section{CHAPTER III}

\section{METHODS}

The purpose of this study was to examine relationships among nursing interventions and pain status during hospitalization in orthopedic surgical patients. This chapter includes a description of the design, sample, sampling, data collection, and analytic procedures. The protection of human subjects is also presented.

\section{Specific Aims}

The specific aims of this study were to (1) describe sociodemographic and clinical characteristics of the sample; (2) examine relationships among the sociodemographic and clinical characteristics, in terms of pain status, of the sample; and (3) identify factors that increase the likelihood of controlled pain during hospitalization of the sample.

\section{Research Design}

A retrospective descriptive correlational design was used to examine the relationship and strength of indicator between nurse-specific pain management variables and pain variation among a sample of patients $(N=1657)$ discharged after a total hip or knee arthroplasty from one of four community hospitals in San Diego, California. Independent variables were patients’ sociodemographic and clinical characteristics, surgeon controlled variables, and nurse controlled variables; the dependent variable was pain status.

\section{Sample and Setting}

All patients discharged after receiving a total hip or knee arthroplasty in one of the four participating community hospitals’ certified orthopedic specialty units between March 1, 2016 and April 30, 2017 were included in the study. Patients receiving anything 
other than an elective single total hip or total knee orthopedic surgical procedure were excluded from the study; thus, patients receiving non-elective or trauma related surgeries were excluded.

The community hospital system is an integrated regional healthcare delivery system that originated in the early 1950s with a single hospital funded by a donation dedicated to veterans. This system expanded to serve the community with four acute care hospitals, three specialty hospitals, three affiliated medical groups, 24 medical centers, five urgent care centers, three skilled nursing facilities, two inpatient rehabilitation centers, home health, hospice, and home infusion programs, numerous outpatient facilities and programs, and a variety of other community health education programs and related services. Two of the four acute care hospitals are Magnet designated. The healthcare system also offers individual and group Health Maintenance Organization (HMO) coverage. Serving a population of approximately 3.3 million in Southern California in 2017, this healthcare system was licensed to operate 2,084 beds and had more than 2,600 affiliated surgeons and 18,000 employees.

\section{Description of the Four Acute Care Hospitals}

Acute care hospital A has 656 licensed beds with the largest combined emergency and trauma center in the county. This hospital provides cancer treatment, organ transplantation, bariatric surgery, heart care, rehabilitation, and a certified orthopedics program. Acute care hospital B has 181 licensed beds providing services including acute, sub-acute and long-term care, liver care, rehabilitation therapies, hospice, emergency services, and a large orthopedics program. Acute care hospital C has 524 licensed beds and is the largest provider of healthcare services in the eastern region of the county with 
one of the busiest emergency departments. This hospital provides services including heart care, oncology, rehabilitation, stroke care, women's health, and a certified orthopedics program. Acute care hospital D has 343 licensed beds and operates as the largest provider of healthcare services in the southern region with the region's busiest emergency department and is home to the region's most comprehensive heart program, cancer treatment, women's and infant's services, and some services for orthopedic care. These four hospitals are part of a not-for-profit public benefit corporation.

\section{Data Collection and Management}

Data were extracted from the Electronic Health Record (EHR), which contained an Orthopedic Pain Data report generated by all participating hospitals. The accuracy of EHR data collected by nurses from standardized fields are assumed to accurately correspond to the reality of the clinical status of the patient for purposes of this study. The report was originally developed to assist orthopedic unit leadership evaluate opportunities for improvement on the units and contains specific EHR brand (Cerner) data fields. An Orthopedic Pain Data report was available containing many of the independent and dependent variables. After receiving IRB approval additional data were provided by the informatics specialists responsible to update the report for the process improvement team. The report helps the orthopedic unit's leadership assess opportunities for improvement on the unit and is updated to include clinically relevant data fields on a regular, ongoing basis for improvement to patient care. The report contained specific EHR brand (Cerner) data field points that were analyzed as secondary data. The dataset contained personal health identifiers (PHI) and was stored on a password-protected server. Patient records were scrubbed of all personal health identifiers (PHI) then 
assigned consecutive numbers for identification by the hospital's informatics specialist prior to access by the researcher. Surgeons were also assigned consecutive numbers for identification. No cross matching occurred to prevent subsequent identification of either patients or surgeons. Only de-identified data were shared with statistical analysis resource personnel outside of the hospital during the analysis phase. The Orthopedic Pain Data report was scrubbed of any data not directly related to this study.

\section{Measurement}

The dependent variable, pain status during hospitalization, was categorized into controlled and uncontrolled pain, with controlled pain defined as actual pain level that is at or below patients' acceptable level of pain. The subjective report of actual pain was measured on a standardized scale of 1-10 and was assessed by the nurse throughout the inpatient admission. The acceptable level of pain was negotiated between the patient and nurse at intake. This data was measured as interval level data. The median pain score was calculated on discharge to determine the subjective report of actual pain during hospitalization. Pain measured by central tendency is supported in the literature for analysis of the patient experience (Duncan \& Haigh, 2013).

The independent variables were selected after a review of literature and with input based on clinical expertise of orthopedic surgical nurses on the designated units. Sociodemographic variables were facility, age, gender, veteran status, and BMI at the time of surgery. Patient-specific clinical characteristics were type of surgery, surgeon, and renal failure (eGFR $<45 \mathrm{mg}$ ). Surgeon controlled variables were nerve block, patient selection in terms of renal failure, with partial control of daily morphine milligram equivalents (MME) day 2 post op and during hospitalization. Nurse controlled variables 
were first ambulation time less than 4 hours post op, first Pasero Opioid Sedation Scale score (POSS) day 2 post op, average time between Nursing Pain Assessments (NPAs) day 2 post op and during hospitalization, and adjunct therapy use day 2 post op and during hospitalization with partial control of daily morphine milligram equivalents (MME) day 2 post op and during hospitalization. Variables outside nurse control were constant to focus on nurse-controlled variables. Increased BMI at the time of surgery has been associated with post op complications and difficult rehabilitations and possibly increased pain (Brown, Loprinzi, Brosky, \& Topp, 2014). Since chronic pain was found to be characteristic for patients receiving elective total hip and knee arthroplasties, the assessment of chronic pain was not included as a variable.

\section{Renal Failure}

The estimated glomerular filtration rate (eGFR) is important to help determine the kidney function of the surgical patient receiving opioids for pain management. Opioids are not well tolerated and may be life-threatening for patients with kidney failure due to decreased rates of excretion (ASPMN, 2018; Pham et al., 2017). Providers must ensure dose modifications of opioid medications for patients with low eGFRs that may result in uncontrolled pain.

\section{Nerve Block}

A nerve block in patients undergoing a total knee arthroplasty, whether continuous or single injection, has been found to improve pain control and shorten rehabilitation time. A patient receiving a nerve block post-surgery is more likely to have controlled pain and require fewer opioid medications (Wegener et al., 2011). A nerve block is ordered and administered by the surgeon outside the control of the nurse; 
however, it is an important covariate to identify the unique contribution to the patient's pain status.

\section{Morphine Equivalent}

Morphine is considered the standard for opioids as the comparative measure for all opioids, which are also known as the most powerful analgesic for patients in pain (Vargas-Schaffer, 2010). The morphine milligram equivalents (MME) is increasingly used as a measure of opioid use. The MME facilitates a comparison between various opioids to establish the amount of opioid a patient has received (Nielsen, Degenhardt, Hoban, \& Gisev, 2016; Sullivan et al., 2009). Morphine is considered the standard unit (1:1) $\mathrm{mg}$ as compared to hydromorphone (1:4) $\mathrm{mg}$, which is four times more powerful (Control \& Prevention, 2016).

\section{First Ambulation}

A multimodal approach to pain treatment to reduce opioid use includes early ambulation, often within four hours of the surgery end time. Early studies of the multimodal approach found patients who were mobilized early had significantly reduced opioid consumption compared to patients who did not mobilize early (Mathiesen et al., 2013). Major orthopedic surgeries occur predominantly in the chronic pain patient population. Early ambulation has been found to contribute to controlled pain, decreased complications, and decreased length of stay (Lombardi, Berend, \& Adams, 2010).

\section{First Pasero Opioid Sedation Scale (POSS)}

A relatively common side effect of opioid administration is sedation resulting in respiratory depression. Opioid-related increased sedation has been shown to have a clinically significant relationship to increased respiratory depression (Nisbet \& Mooney- 
Cotter, 2009). Opioid-induced sedation may be represented as a continuum of levels of consciousness that may be measured by nurses in the clinical setting using a reliable and valid sedation assessment instrument. Frequent and ongoing nursing assessments are necessary because sedation is not directly related to opioid serum levels. Because sedation always precedes respiratory depression, consistent assessment of sedation empowers the nurse to have a significant role in preventing opioid-related complications. The POSS was developed for use as a sedation scale for serial sedation assessments during opioid administration to detect sedation and prevent opioid-related adverse events (Pasero, 2009; Pasero \& McCaffery, 2002). Nurses’ have reported increased confidence in their clinical decision-making abilities through the use of the scale. The POSS demonstrated strong interrater reliability with the highest applicability for measurement in the post op setting to detect unintentional sedation resulting in respiratory depression. The POSS (Cronbach alpha $=0.903)$ demonstrates acceptable reliability and validity (Nisbet, et al. 2009) The POSS provides a structured sedation assessment with 5 levels of sedation (1-5) and interventions at each level to support clinical decision-making in relationship to opioid administration for pain control. 
Table 1. Description of Pasero Opioid-Induced Sedation Scale with Interventions (Pasero, 2009)

S= Sleep, easy to arouse

*Acceptable; no action necessary; may increase opioid dose if needed

$1=$ Awake and alert

*Acceptable; no action necessary; may increase opioid dose if needed

$2=$ Slightly drowsy, easily aroused

*Acceptable; no action necessary; may increase opioid dose if needed

3= Frequently drowsy, arousable, drifts off to sleep during conversation

*Unacceptable; monitor respiratory status and sedation level closely until sedation level is less than 3 and respiratory status is satisfactory; decrease opioid dose $25 \%$ to $50 \%$ or notify prescriber or anesthesiologist for orders; consider administering a non-sedating, opioid sparing non-opioid, such as acetaminophen or a NSAID, if not contraindicated.

4= Somnolent, minimal or no response to verbal and physical stimulation

*Unacceptable; stop opioid; consider administering naloxone; notify prescriber or anesthesiologist; monitor respiratory status and sedation level closely until sedation level is stable at less than 3 and respiratory status is satisfactory.

*Intervention associated with sedation level.

Copyright Pasero C, 1994. Used with author permission.

Serial POSS assessments facilitate ongoing clinical decision making; however, for the purposes of this study the first nursing POSS assessment was the baseline assessment that was compared in relationship to day 2 post op and overall pain control.

\section{Time Between Nursing Pain Assessments (NPAs)}

The average time between NPAs is a specific nursing care indicator

demonstrating a construct within the control of the nurse (Carroll et al., 1999). Nurses

may reduce variation in pain through improved assessment times. Increased time between

nursing assessments increases the likelihood the patient will have uncontrolled pain

(Jarzyna et al., 2011; Vargas-Schaffer \& Cogan, 2014). The ideal time between nursing

assessments was studied to determine the timeframe required to achieve controlled pain

(Cveykus \& Carter, 2006). This study seeks to identify optimal time between nursing

assessments to inform the creation of standardized nursing work that is operating within

the specified timing because every task, work step, cycle, or distance has an appropriate 
time window for optimal outcomes. Increased frequency of pain assessments may be required to assist patients in reaching their pain management goals. Variation in nursing pain assessment practices will be evaluated to facilitate the development of informed standardized nursing work (Graban, 2011).

\section{Surgeon}

A total of 33 different surgeons practicing in the four participating hospitals completed the total hip and total knee arthroplasties. The variable surgeon was also grouped into six categories based on the number of surgeries performed during the study. The six categories are: $1=1$ to 29 surgeries, $2=30$ to 59 surgeries, $3=60$ to 89 surgeries, $4=90$ to 119 surgeries, $5=120$ to 139 surgeries, and $6=140$ to 247 surgeries.

All study variables were examined for normality, missing values, and outliers. Summary statistics were calculated including frequencies for categorical variables and means for continuous variables. Bivariate associations among categorical sociodemographic and clinical variables and pain status were analyzed using chi-square; continuous sociodemographic and clinical variables and pain status were analyzed using one-way analysis of variance. Variables significant at $p<.05$ in the bivariate analysis were considered for entry into a saturated logistic regression model to identify factors that increase the likelihood of controlled pain during hospitalization of orthopedic surgical patients after a total hip or total knee arthroplasty. For the logistic regression analysis, controlled pain was defined as pain that was at or below the patient's tolerable level of pain by subjective assessment (Controlled pain status = Actual pain level reported by patients $\leq$ Patients' acceptable level pain.) Variables considered for entry in the logistic regression model were examined for linearity, multicollinearity, and outliers. 


\section{Human Subjects Protections}

This study was reviewed and approved by the health system and University of San Diego Institutional Review Boards (Appendix D). The study is a retrospective analysis of secondary data. All data were obtained via hospitals’ EHR, which had an orthopedic pain data report containing the dependent and all independent variables of interest for the study. The dataset contained personal health identifiers (PHI) stored on a hospital password-protected server. Patient records were scrubbed of all PHI and then assigned consecutive numbers for identification. Surgeons were assigned consecutive numbers for identification. No cross matching occurred to prevent subsequent identification of either the patients or the surgeons. Only de-identified data were shared with statistical analysis resource personnel outside of the hospital during the analysis phase. The orthopedic pain data report was scrubbed of any data not directly related to this study. 


\section{CHAPTER IV}

\section{RESULTS}

The purpose of this study was to examine relationships among nursing interventions and pain status during hospitalization in orthopedic surgical patients. In this chapter study results are presented.

\section{Sociodemographic and Clinical Characteristics of Study Population}

Sociodemographic and clinical characteristics of the 1,647 study participants overall and by type of orthopedic surgery are presented in Tables 2 and 3. The study included data for all patients discharged after receiving a total hip or total knee arthroplasty in one of four community hospital facilities between March 1, 2016 and April 30, 2017. In this sample, 65.3\% $(n=1065)$ of patients reported controlled pain during hospitalization and 34.7\% $(n=566)$ uncontrolled, with 64.6\% $(n=573)$ of patients in the total knee arthroplasty group reporting uncontrolled pain versus $66.1 \%$ (n $=492$ ) in the total hip arthroplasty group. There were 506 orthopedic surgical patients from hospital 1 (30.5\%), 548 from hospital 2 (33.1\%), 572 from hospital 3 (34.5\%); and 31 from hospital 4 (1.9\%). Females represented 59.7\% of the overall sample, with $64.5 \%$ women discharged after total hip and 54\% women discharged after total knee arthroplasty. Patients’ average age was $66.09(S D=10.38)$ years; average age ranged from 35 to 94 for the total knee arthroplasty group and 28 to 100 for the total hip arthroplasty group. Patients’ average BMI at time of surgery was $30.75(S D=6.26)$; average BMI ranged from 14 to 61.9 for the total knee arthroplasty group and 14 to 53 for the total hip arthroplasty group.

Patients’ daily average MME during hospitalization was $1.09 \mathrm{mg} / \mathrm{hr}(S D=0.87)$. 
This rate was notably higher for patients’ daily average MME day 2 post op $(M=1.32$ $\mathrm{mg} / \mathrm{hr}, S D=1.04)$. Patients' average eGFR values were $58.98 \mathrm{~mL} / \mathrm{mi}(S D=5.39)$, with comparable rates for the total knee $(M=58.81, S D=5.87)$ and total hip arthroplasty groups $(M=59.17, S D=4.80)$. The average time between NPAs during hospitalization was 124.05 minutes $(S D=43.23)$, which was remarkably higher on day 2 post op $(M=$ 176.87, $S D=116.25)$. The large standard deviations values, coupled with the large maximum times, are likely a result of recording errors in the EHR.

Table 2

Sociodemographic and Clinical Characteristics of Study Population $(N=1,657)$

\begin{tabular}{|c|c|c|c|c|c|c|}
\hline \multirow[b]{2}{*}{ Characteristic } & \multicolumn{2}{|c|}{ Total } & \multicolumn{2}{|c|}{$\begin{array}{l}\text { Total Knee } \\
\text { Arthroplasty }\end{array}$} & \multicolumn{2}{|c|}{$\begin{array}{c}\text { Total Hip } \\
\text { Arthroplasty }\end{array}$} \\
\hline & $n$ & $\%$ & $n$ & $\%$ & $n$ & $\%$ \\
\hline \multicolumn{7}{|l|}{ Facility } \\
\hline Hospital 1 & 506 & 30.5 & 263 & 29.1 & 243 & 32.3 \\
\hline Hospital 2 & 548 & 33.1 & 335 & 37.1 & 213 & 28.3 \\
\hline Hospital 3 & 572 & 34.5 & 288 & 31.9 & 284 & 37.7 \\
\hline Hospital 4 & 31 & 1.9 & 18 & 2.0 & 13 & 1.7 \\
\hline \multicolumn{7}{|l|}{ Gender } \\
\hline Female & 966 & 59.7 & 564 & 64.5 & 402 & 54.0 \\
\hline Male & 652 & 40.3 & 310 & 35.5 & 342 & 46.0 \\
\hline \multicolumn{7}{|l|}{ Veteran Status } \\
\hline Veteran & 160 & 11.4 & 93 & 12.0 & 67 & 10.6 \\
\hline Civilian & 1248 & 88.6 & 684 & 88.0 & 564 & 89.4 \\
\hline \multicolumn{7}{|l|}{ Type of Surgery } \\
\hline Total Knee Arthroplasty & 904 & 54.6 & -- & -- & -- & -- \\
\hline Total Hip Arthroplasty & 753 & 45.4 & -- & -- & -- & -- \\
\hline \multicolumn{7}{|c|}{ Pain Status During Hospitalization } \\
\hline Controlled & 1065 & 65.3 & 573 & 64.6 & 492 & 66.1 \\
\hline \multirow[t]{2}{*}{ Uncontrolled } & 566 & 34.7 & 324 & 35.3 & 252 & 33.9 \\
\hline & $M$ & $S D$ & $M$ & $S D$ & $M$ & $S D$ \\
\hline Age & 66.09 & 10.38 & 67.40 & 9.25 & 64.51 & 11.40 \\
\hline BMI at Time of Surgery & 30.75 & 6.26 & 31.03 & 6.44 & 30.42 & 6.03 \\
\hline Renal Failure $(\mathrm{eGFR}<45)$ & 58.98 & 5.39 & 58.81 & 5.87 & 59.17 & 4.80 \\
\hline
\end{tabular}

Note. BMI=Body Mass Index; eGFR=Estimated Glomerular Filtration Rate; $M=$ Mean; $S D=$ Standard Deviation; Controlled pain status=actual pain level reported by patients $\leq$ patients' acceptable level pain. 
Table 3

Pain Management Interventions after Total Hip or Total Knee Arthroplasty $(N=1657)$

\begin{tabular}{|c|c|c|c|c|c|c|}
\hline \multirow[b]{2}{*}{ Characteristic } & \multicolumn{2}{|c|}{ Total } & \multicolumn{2}{|c|}{$\begin{array}{c}\text { Total Knee } \\
\text { Arthroplasty }\end{array}$} & \multicolumn{2}{|c|}{$\begin{array}{l}\text { Total Hip } \\
\text { Arthroplasty }\end{array}$} \\
\hline & $n$ & $\%$ & $n$ & $\%$ & $n$ & $\%$ \\
\hline \multicolumn{7}{|l|}{ Evaluation of Pain during Hospitalization ${ }^{\mathrm{a}}$} \\
\hline No pain & 334 & 20.2 & 188 & 20.8 & 146 & 19.4 \\
\hline Mild pain & 645 & 38.9 & 337 & 37.3 & 308 & 41.0 \\
\hline Moderate pain & 556 & 33.6 & 300 & 33.2 & 256 & 34.0 \\
\hline Severe pain & 121 & 7.3 & 79 & 8.7 & 42 & 5.6 \\
\hline \multicolumn{7}{|l|}{ Evaluation of Pain Day 2 Post $\mathrm{Op}^{\mathrm{a}}$} \\
\hline No pain & 160 & 9.7 & 97 & 10.7 & 63 & 8.4 \\
\hline Mild pain & 583 & 35.2 & 318 & 35.2 & 265 & 35.2 \\
\hline Moderate pain & 713 & 43.0 & 373 & 41.3 & 340 & 45.2 \\
\hline Severe pain & 201 & 12.1 & 116 & 12.8 & 85 & 11.3 \\
\hline \multicolumn{7}{|l|}{ 1st POSS Day 2 Post Op } \\
\hline Sleep, easy to arouse & 95 & 6.4 & 53 & 6.6 & 42 & 6.2 \\
\hline Awake and alert & 925 & 62.7 & 505 & 63.4 & 420 & 61.9 \\
\hline Slightly drowsy, easily aroused & 301 & 20.4 & 168 & 21.1 & 133 & 19.6 \\
\hline $\begin{array}{l}\text { Frequently drowsy, arousable, drifts off } \\
\text { to sleep during conversation }\end{array}$ & 103 & 7.0 & 48 & 6.0 & 55 & 8.1 \\
\hline $\begin{array}{l}\text { Somnolent, minimal or no response to } \\
\text { verbal and physical stimulation }\end{array}$ & 52 & 3.5 & 23 & 2.9 & 29 & 4.3 \\
\hline \multicolumn{7}{|l|}{ Nerve block } \\
\hline Yes & 1001 & 60.6 & 541 & 60.0 & 460 & 61.3 \\
\hline No & 651 & 39.4 & 360 & 40.0 & 291 & 38.7 \\
\hline \multicolumn{7}{|l|}{ Ambulation time $<4$ Hours Post Op } \\
\hline Yes & 1335 & 80.9 & 727 & 80.6 & 608 & 81.2 \\
\hline No & 316 & 19.1 & 175 & 19.4 & 141 & 18.8 \\
\hline \multicolumn{7}{|l|}{ Aromatherapy during Hospitalization } \\
\hline Yes & 537 & 32.4 & 264 & 29.2 & 273 & 36.3 \\
\hline \multirow[t]{2}{*}{ No } & 1120 & 67.6 & 640 & 70.8 & 480 & 63.7 \\
\hline & $M$ & $S D$ & $M$ & $S D$ & $M$ & $S D$ \\
\hline Min. between NPAs during Hospitalization & 124.05 & 43.23 & 125.06 & 41.88 & 122.84 & 44.79 \\
\hline Min. between NPAs Day 2 Post Op & 176.87 & 116.25 & 183.35 & 127.68 & 169.09 & 100.38 \\
\hline Daily MME during Hospitalization & 1.09 & 0.87 & 1.15 & 0.86 & 1.01 & 0.88 \\
\hline Daily MME Day 2 Post Op & 1.25 & 1.03 & 1.32 & 1.04 & 1.15 & 1.01 \\
\hline
\end{tabular}

Note. $M$ = Mean; MME = Milligram Morphine Equivalent; NPAs = Nursing Pain Assessments; POSS = Pasero Opioid-induced Sedation Scale; Post Op = Post-operative; $S D=$ Standard Deviation. ${ }^{\text {a } A c t u a l ~ p a i n ~}$ level reported by patients. 


\section{Sociodemographic and Clinical Characteristics of Study Population by Pain Status}

Chi-square and Fisher's exact tests for association were conducted between all categorical variables and pain status during hospitalization (Table 3). There was a statistically significant difference between pain status during hospitalization and:

Whether a nerve block was administered, $\chi^{2}(1)=10.23, p=.002$, Phi $=.079$ (small effect); $1^{\text {st }}$ POSS assessment, $\chi^{2}(4)=16.81, p=.002$, Cramer's V = .108 (small effect); aromatherapy use during hospitalization, $\chi^{2}(1)=24.13, p<.001$, Phi $=.122$ (small effect); comfort massage use during hospitalization, $\chi^{2}(1)=11.39, p=.001$, Phi $=.084$ (small effect); aromatherapy use day 2 post op, $\chi^{2}(1)=17.41, p<.001$, Phi $=.103$ (small effect); and comfort massage use day 2 post op, $\chi^{2}(1)=8.54, p=.003$, Phi $=.072$ (small effect). There were no statistically significant differences between patients reporting controlled vs. uncontrolled pain during hospitalization in terms of gender, veteran status, type of surgery, ambulation time $<4$ hours post op, and other adjunct therapies such as acupuncture and music therapy. 
Table 4

Differences in Pain during Hospitalization after Total Hip or Total Knee Arthroplasty: Chi-square $(N=1657)$

\begin{tabular}{|c|c|c|c|c|c|c|}
\hline \multirow[b]{2}{*}{ Characteristic } & \multicolumn{2}{|c|}{ Uncontrolled Pain } & \multicolumn{2}{|c|}{ Controlled Pain } & \multirow[b]{2}{*}{$\chi^{2}$} & \multirow[b]{2}{*}{$p$} \\
\hline & $n$ & $\%$ & $n$ & $\%$ & & \\
\hline Gender $^{\mathrm{a}}$ & & & & & 0.89 & .362 \\
\hline Female & 342 & 35.9 & 611 & 64.1 & & \\
\hline Male & 215 & 33.6 & 425 & 66.4 & & \\
\hline Veteran Status $^{\mathrm{a}}$ & & & & & 1.30 & .291 \\
\hline Veteran & 50 & 31.4 & 109 & 68.6 & & \\
\hline Civilian & 442 & 36.1 & 784 & 63.9 & & \\
\hline Type of Surgery ${ }^{\mathrm{a}}$ & & & & & 0.42 & .531 \\
\hline Total hip & 252 & 33.9 & 492 & 66.1 & & \\
\hline Total knee & 314 & 35.4 & 573 & 64.6 & & \\
\hline 1st POSS Day 2 Post Op & & & & & 16.81 & .002 \\
\hline Sleep, easy to arouse & 26 & 27.7 & 68 & 72.3 & & \\
\hline Awake and alert & 289 & 31.8 & 620 & 68.2 & & \\
\hline Slightly drowsy, easily aroused & 33 & 32.4 & 69 & 67.6 & & \\
\hline $\begin{array}{l}\text { Frequently drowsy, arousable, drifts } \\
\text { off to sleep during conversation } \\
\text { Somnolent, minimal or no response to } \\
\text { verbal and physical stimulation }\end{array}$ & 16 & 30.8 & 36 & 69.2 & & \\
\hline Nerve block ${ }^{\mathrm{a}}$ & & & & & 10.23 & .002 \\
\hline Yes & 310 & 31.6 & 672 & 68.4 & & \\
\hline No & 253 & 39.3 & 391 & 60.7 & & \\
\hline Ambulation time $<4$ Hours Post Op ${ }^{a}$ & & & & & 1.38 & .260 \\
\hline Yes & 465 & 35.4 & 850 & 64.6 & & \\
\hline No & 99 & 31.8 & 212 & 68.2 & & \\
\hline Aromatherapy during Hospitalization ${ }^{\mathrm{a}}$ & & & & & 24.13 & $<.001$ \\
\hline Yes & 141 & 26.4 & 393 & 73.6 & & \\
\hline No & 425 & 38.7 & 672 & 61.3 & & \\
\hline
\end{tabular}

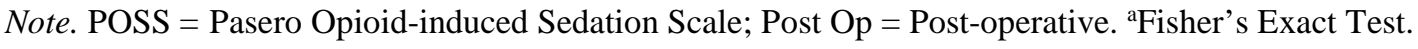

One-way between groups Analysis of Variance (ANOVA) was conducted between all continuous variables and pain status during hospitalization (Table 4). The 
following continuous variables were evaluated: Age, BMI at the time of surgery, daily MME during hospitalization, daily MME day 2 post op, renal failure, time between nursing pain assessments during hospitalization, time between nursing pain assessments day 2 post op. Pain status was categorized into controlled and uncontrolled pain. Homogeneity of variances was assessed by Levene's test of homogeneity of variances; Welch robust test for equality of means are reported for those significant ANOVA results that do not meet the homogeneity of variance assumption.

Age was statistically significantly different for patients with controlled and uncontrolled pain during hospitalization $(F[1,1629]=4.205, p=.040)$. Age was higher for those with uncontrolled pain $(M=66.85, S D=10.34)$ than for those in the controlled pain group $(M=65.74, \mathrm{SD}=10.40)$. BMI at the time of surgery was also statistically significantly different for patients with controlled and uncontrolled pain during hospitalization $($ Welch $F[1,947]=23.695, p=.001)$. BMI was higher for those with uncontrolled pain $(M=31.88, S D=6.72)$ than for those with controlled pain $(M=30.16$, $\mathrm{SD}=5.96$ ). Time between nursing pain assessment during hospitalization was statistically significantly different for patients with controlled and uncontrolled pain during hospitalization $($ Welch $F[1,1214]=4.787, p=.029)$. Time between nursing pain assessment during hospitalization was lower for those with uncontrolled pain $(M=$ $120.33, S D=39.25)$ than for those with controlled pain $(M=124.89, S D=41.69)$. Time between nursing pain assessment day 2 post op was statistically significantly different for patients with controlled and uncontrolled pain during hospitalization (Welch $F[1,1281]$ $=19.402, p<.001)$. Time between nursing pain assessment during hospitalization was lower for those with uncontrolled pain $(M=158.49, S D=105.17)$ than for those with 
controlled pain $(M=183.74, S D=118.92)$.

Daily MME during hospitalization and day 2 post op were not significantly associated with pain status during hospitalization; although daily MME on day 2 post op approached significance (Welch $F[1,1181]=3.693, p=.055)$, suggesting opioids may not be as needed for patients in the controlled pain group, especially after day 2 post op. Table 5 Differences in Pain Status during Hospitalization after Total Hip or Knee Arthroplasty: One-Way ANOVA $(N=1,657)$

\begin{tabular}{|c|c|c|c|c|c|}
\hline Characteristic & $\begin{array}{c}\begin{array}{c}\text { Uncontrolled } \\
\text { Pain }\end{array} \\
M(S D)\end{array}$ & $\begin{array}{c}\begin{array}{c}\text { Controlled } \\
\text { Pain }\end{array} \\
M(S D)\end{array}$ & $F(d f)$ & $p$ & $\eta^{2}$ \\
\hline Age & $66.85(10.34)$ & $\begin{array}{c}65.74 \\
(10.40)\end{array}$ & $\begin{array}{c}4.21 \\
(1,1629)\end{array}$ & .040 & .003 \\
\hline BMI at Time of Surgery & $31.88(6.72)$ & $\begin{array}{l}30.16 \\
(5.96)\end{array}$ & $\begin{array}{c}23.70 \\
(1,947)\end{array}$ & $<.001$ & .017 \\
\hline Renal Failure $(\mathrm{eGFR}<45)$ & $59.13(4.29)$ & $\begin{array}{l}58.94 \\
(5.70)\end{array}$ & $\begin{array}{c}0.22 \\
(1,916)\end{array}$ & .638 & .000 \\
\hline Min. between NPAs during & 120.33 & 124.89 & 4.79 & .029 & .003 \\
\hline Hospitalization & $(39.24)$ & (41.69) & $(1,1214)$ & & \\
\hline Min. between NPAs Day 2 & 158.49 & 183.74 & 19.40 & $<.001$ & .011 \\
\hline $\begin{array}{l}\text { Daily MME during } \\
\text { Hospitalization }\end{array}$ & $1.04(0.80)$ & $1.11(0.91)$ & $\begin{array}{c}(1,1281) \\
3.08 \\
(1,1273)\end{array}$ & .080 & .002 \\
\hline Daily MME Day 2 Post Op & $1.18(0.93)$ & $1.28(1.08)$ & $\begin{array}{c}3.69 \\
(1,1181)\end{array}$ & .055 & .002 \\
\hline
\end{tabular}

Note. $d f=$ degrees of freedom; $\eta^{2}=$ eta squared; $M=$ Mean; MME = Milligram Morphine Equivalent; NPAs = Nursing Pain Assessments; Post Op = Post-operative; $S D=$ Standard Deviation. ${ }^{a}$ Welch robust test for equality of means reported for ANOVA results that do not meet the homogeneity of variance assumption.

Surgeons and pain status. Chi-square tests for association were conducted between the 33 orthopedic surgeons who completed the total knee or total hip arthroplasty and pain status (controlled, uncontrolled; Table 5; Figure 2). Almost half the cells had expected cell frequencies less than 5; chi-square was not produced. Figure 2 
shows a general trend: surgeons with greater number of surgeries had more patients with controlled (vs. uncontrolled) pain during hospitalization. Of note, surgeon 17 with 247 (14.9\%) surgeries had 187 (76.6\%) patients with controlled pain and 57 (23.4\%) patients with uncontrolled pain. Yet, surgeon 9 with 216 (13.1\%, almost the same number of surgeries as surgeon 17) had 107 (50.2\%) patients with controlled pain and 106 (49.8\%) with uncontrolled pain.

In order to clarify the impact of surgeon on pain status, surgeons were grouped by the number of surgeries performed to study patients during the duration of the study. About $40 \%$ of surgeries were performed by surgeons with the most experience (Table 6). Chi-square tests indicated there was a statistically significant difference between pain status during hospitalization and surgeon experience (based on number of surgeries performed during the study, $\chi^{2}(5)=21.20, p=.001$, Cramer's V $=.114$ (small effect). 
Table 6. Prevalence of Patients' Pain Status during Hospitalization after Total Hip or Total Knee Arthroplasty by Surgeon $(N=1629)$

\begin{tabular}{|c|c|c|c|c|c|c|}
\hline \multirow[b]{2}{*}{ Characteristic } & \multicolumn{2}{|c|}{ Total } & \multicolumn{2}{|c|}{ Uncontrolled Pain } & \multicolumn{2}{|c|}{ Controlled Pain } \\
\hline & $n$ & $\%$ & $n$ & $\%$ & $n$ & $\%$ \\
\hline Surgeon 1 & 116 & 7.0 & 53 & 45.7 & 63 & 54.3 \\
\hline Surgeon 2 & 1 & 0.1 & 1 & 0.3 & 0 & 0.7 \\
\hline Surgeon 3 & 26 & 1.6 & 2 & 7.7 & 24 & 92.3 \\
\hline Surgeon 4 & 27 & 1.6 & 5 & 18.5 & 22 & 81.5 \\
\hline Surgeon 5 & 8 & 0.5 & 2 & 28.6 & 5 & 71.4 \\
\hline Surgeon 6 & 53 & 3.2 & 15 & 28.3 & 38 & 71.7 \\
\hline Surgeon 7 & 1 & 0.1 & 1 & 100.0 & 0 & 0.0 \\
\hline Surgeon 8 & 61 & 3.7 & 23 & 38.3 & 37 & 61.7 \\
\hline Surgeon 9 & 216 & 13.1 & 106 & 49.8 & 107 & 50.2 \\
\hline Surgeon 10 & 2 & 0.1 & 0 & 0.0 & 2 & 100.0 \\
\hline Surgeon 11 & 38 & 2.3 & 11 & 29.7 & 26 & 70.3 \\
\hline Surgeon 12 & 194 & 11.7 & 61 & 31.9 & 130 & 68.1 \\
\hline Surgeon 13 & 14 & 0.8 & 4 & 28.6 & 10 & 71.4 \\
\hline Surgeon 14 & 71 & 4.3 & 18 & 26.9 & 49 & 73.1 \\
\hline Surgeon 15 & 67 & 4.0 & 36 & 53.7 & 31 & 46.3 \\
\hline Surgeon 16 & 1 & 0.1 & 0 & 0.0 & 1 & 100.0 \\
\hline Surgeon 17 & 247 & 14.9 & 57 & 23.4 & 187 & 76.6 \\
\hline Surgeon 18 & 139 & 8.4 & 29 & 21.8 & 104 & 78.2 \\
\hline Surgeon 19 & 62 & 3.7 & 32 & 51.6 & 30 & 48.4 \\
\hline Surgeon 20 & 2 & 0.1 & 0 & 0.0 & 2 & 100.0 \\
\hline Surgeon 21 & 3 & 0.2 & 2 & 66.7 & 1 & 33.3 \\
\hline Surgeon 22 & 5 & 0.3 & 2 & 40.0 & 3 & 60.0 \\
\hline Surgeon 23 & 132 & 8.0 & 40 & 31.3 & 88 & 68.8 \\
\hline Surgeon 24 & 1 & 0.1 & 0 & 0.0 & 1 & 100.0 \\
\hline Surgeon 25 & 31 & 1.9 & 9 & 29.0 & 22 & 71.0 \\
\hline Surgeon 26 & 7 & 0.4 & 1 & 14.3 & 6 & 85.7 \\
\hline Surgeon 27 & 13 & 0.8 & 7 & 53.8 & 6 & 46.2 \\
\hline Surgeon 28 & 85 & 5.1 & 37 & 43.5 & 48 & 56.5 \\
\hline Surgeon 29 & 5 & 0.3 & 3 & 60.0 & 2 & 40.0 \\
\hline Surgeon 30 & 1 & 0.1 & 1 & 100.0 & 0 & 0.0 \\
\hline Surgeon 31 & 24 & 1.5 & 8 & 33.3 & 16 & 66.7 \\
\hline Surgeon 32 & 1 & 0.1 & 0 & 0.0 & 1 & 100.0 \\
\hline Surgeon 33 & 1 & 0.1 & 0 & 0.0 & 1 & 100.0 \\
\hline
\end{tabular}




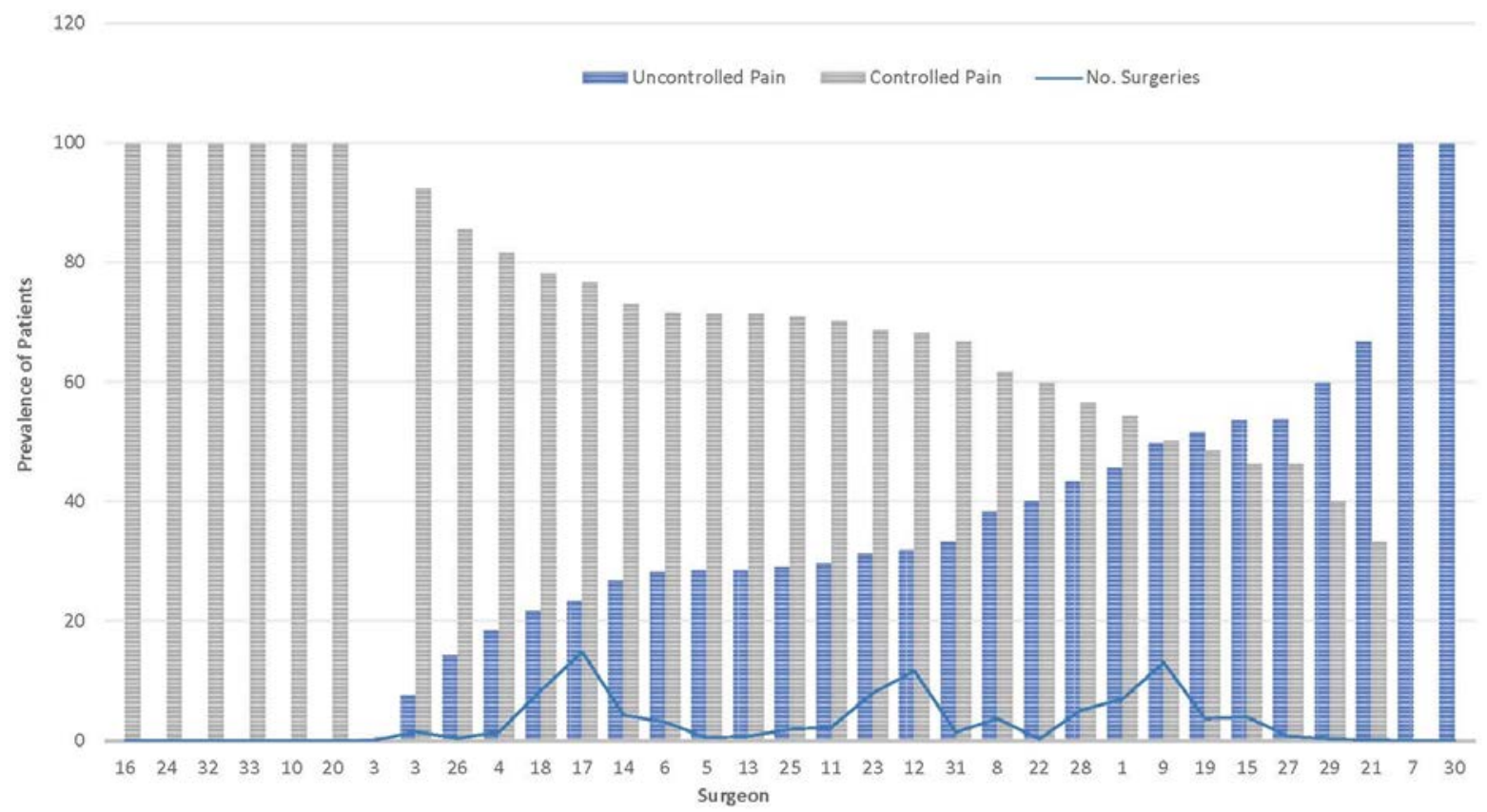

Figure 2. Prevalence of patients reporting controlled pain vs. uncontrolled pain during hospitalization after total hip or knee arthroplasty by surgeon performing the surgery.

Table 7

Prevalence of Patients' Pain Status during Hospitalization after Total Hip or Total Knee Arthroplasty by Surgeon Experience $(N=1629)$

\begin{tabular}{lcccccc}
\hline & \multicolumn{2}{c}{ Total } & \multicolumn{2}{c}{ Uncontrolled Pain } & \multicolumn{2}{c}{ Controlled Pain } \\
Characteristic & $\boldsymbol{n}$ & $\mathbf{\%}$ & $\boldsymbol{n}$ & $\mathbf{\%}$ & $\boldsymbol{n}$ & \% \\
\hline Surgeon Group 1 & 143 & 8.6 & 39 & 27.5 & 103 & 72.5 \\
Surgeon Group 2 & 122 & 7.4 & 35 & 28.9 & 86 & 71.1 \\
Surgeon Group 3 & 190 & 11.5 & 91 & 48.1 & 98 & 51.9 \\
Surgeon Group 4 & 156 & 9.4 & 55 & 36.2 & 97 & 63.8 \\
Surgeon Group 5 & 387 & 23.4 & 122 & 32.4 & 255 & 67.6 \\
Surgeon Group 6 & 657 & 39.7 & 224 & 34.6 & 426 & 65.4 \\
\hline
\end{tabular}

Note. Surgeon Group 1=1-29 arthroplasties during the study duration; Surgeon Group 2=30-59; Surgeon Group 3-60-89; Surgeon Group 4=90-119; Surgeon Group 5=120-139; Surgeon Group 6=140-247.

\section{Predictors of Controlled Pain}

A binomial logistic regression analysis was conducted to examine the effects of 
BMI at the time of surgery, surgeon group, nerve block, MME day 2 post op, $1^{\text {st }}$ POSS day 2 post op, time between nurse pain assessments day 2 post op, and aromatherapy during hospitalization on the likelihood of patients reporting controlled pain during hospitalization following total hip or total knee arthroplasty (Table 7). Linearity of the continuous variables with respect to the logit of the dependent variable was assessed using the Box-Tidwell (1962) procedure; all continuous independent variables were found to be linearly related to the logit of the dependent variable. A test of the overall model against a constant only model was statistically significant, $\chi^{2}(14)=122.47, p<$ .001 , indicating the variables reliably predicted pain status during hospitalization. The Nagelkerke’s $\mathrm{R}^{2}$ of .124 indicated a predictor model with an overall prediction success of 68.2 (24.8\% for patients with uncontrolled pain and $90.8 \%$ for patients with controlled pain during hospitalization). The Wald statistic indicates aromatherapy during hospitalization, nerve block, time between nursing pain assessments, BMI, surgeon group, and $1^{\text {st }}$ POSS day 2 post op make significant contributions to the model. Those patients who received aromatherapy during hospitalization and a nerve block were more likely to have controlled pain, as were those patients with lower BMI. Patients with longer time between nurse pain assessments on day 2 post op were more likely to have their pain controlled during hospitalization, which may represent the appropriate responsiveness of the nurse to patients with uncontrolled pain compared to those with controlled pain in in this hospital setting.

Patients with surgeons who completed between 60 and 89 arthroplasties during the length study and those slightly drowsy and/or easily aroused were more likely to experience uncontrolled pain during hospitalization. 
Table 8

Logistic Regression Analysis Predicting Pain Status during Hospitalization after Total Hip

or Knee Arthroplasty $(N=1192)$

\begin{tabular}{|c|c|c|c|c|c|c|}
\hline Predictor & $\boldsymbol{B}$ & $S E$ & OR & $95 \% C I$ & Wald & $p$ \\
\hline BMI at Time of Surgery & -0.04 & 0.01 & 0.96 & {$[0.94,0.98]$} & 13.91 & $<.001$ \\
\hline Nerve Block & 0.31 & 0.13 & 1.36 & {$\left[\begin{array}{ll}1.05 & 1.77\end{array}\right]$} & 5.36 & .021 \\
\hline Daily MME Day 2 Post Op & 0.05 & 0.07 & 1.05 & {$[0.92,1.20]$} & 0.52 & .473 \\
\hline Min. btw Nursing Pain & 0.01 & 0.01 & 1.01 & {$[1.01,1.01]$} & 43.73 & $<.001$ \\
\hline \multicolumn{7}{|l|}{ Assessments Day 2 Post Op } \\
\hline Surgeon Group 2 & -0.39 & 0.28 & 0.68 & {$[0.40,1.17]$} & 1.94 & .164 \\
\hline Surgeon Group 3 & -0.61 & 0.30 & 0.54 & {$[0.30,0.97]$} & 4.25 & .039 \\
\hline Surgeon Group 4 & -0.28 & 0.35 & 0.76 & {$[0.38,1.51]$} & 0.63 & .427 \\
\hline Surgeon Group 5 & -0.26 & 0.43 & 0.77 & {$[0.33,1.78]$} & 0.38 & .538 \\
\hline $1^{\text {st }}$ POSS Day 2 Post Op & -0.24 & 0.34 & 0.7 & {$[0.41,1.52]$} & 0.51 & .474 \\
\hline Awake and Alert & -0.85 & 0.32 & 0.43 & {$[0.23,0.80]$} & 6.93 & .008 \\
\hline Slightly drowsy, easily aroused & -0.37 & 0.33 & 0.69 & {$[0.36,1.34]$} & 1.20 & .274 \\
\hline $\begin{array}{l}\text { Frequently drowsy, arousable, } \\
\text { drifts off to sleep during } \\
\text { conversation }\end{array}$ & -0.36 & 0.28 & 0.70 & {$[0.40,1.21]$} & 1.63 & .202 \\
\hline $\begin{array}{l}\text { Somnolent; minimal or no } \\
\text { response to verbal and physical } \\
\text { stimulation }\end{array}$ & -0.48 & 0.27 & 0.62 & {$[0.37,1.04]$} & 3.24 & .072 \\
\hline $\begin{array}{l}\text { Aromatherapy during } \\
\text { hospitalization }\end{array}$ & 0.86 & 0.16 & 2.37 & {$[1.74,3.24]$} & 29.35 & $<.001$ \\
\hline $\begin{array}{l}\chi^{2}(14)=122.47^{* * *} \\
-2 \text { Log likelihood = 1407.66. } \\
\text { Nagelkerke } R^{2}=13.5 \%\end{array}$ & & & & & & \\
\hline \multicolumn{7}{|c|}{ 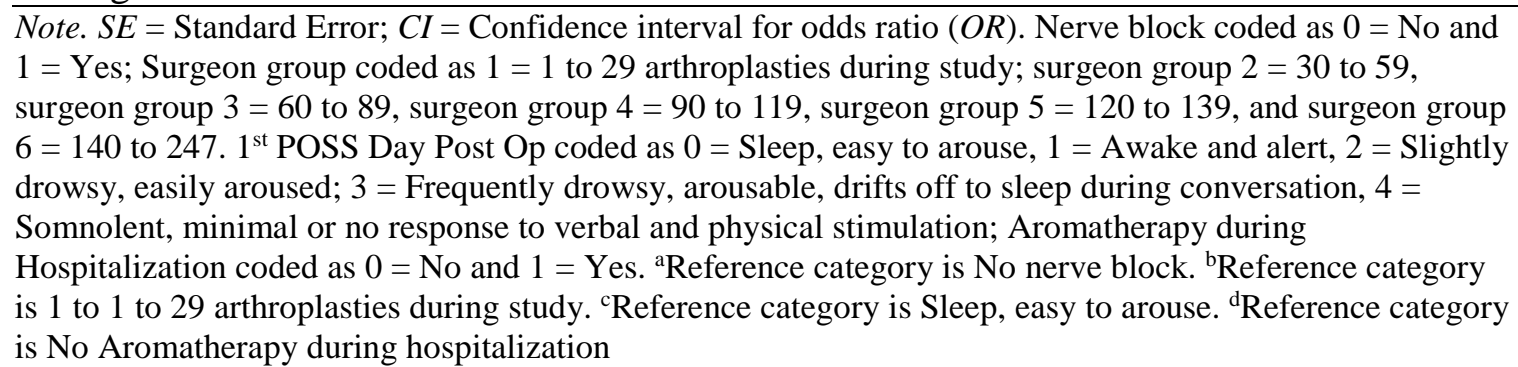 } \\
\hline
\end{tabular}




\section{Adjunct Therapy Use}

Adjunct therapy use for all study participants on day 2 post op and during hospitalization is presented in Table 8. Frequencies and percentages were calculated for the multiple response variables, adjunct therapy use day 2 post op, and adjunct therapy use during hospitalization. Out of 1,657 patients included in the study, 1,844 responses were generated with regards to adjunct therapy use day 2 post op (several patients reported using more than one adjunct therapy) and 2,005 responses during hospitalization. Out of the 1,844 responses generated on day 2 post op, the adjunct therapy selected most often was aromatherapy with $25.5 \%$ of responses $(n=422)$, followed by comfort massage with $11.3 \%$ of responses $(n=188)$. These results were slightly higher during patients’ hospitalization. Out of the 2,005 responses generated during hospitalization, 26.8\% $(n=537)$ indicated aromatherapy use and 17\% $(n=340)$ comfort massage. Acupuncture and music therapy use was very infrequent both day 2 post op and during hospitalization.

Of note, aromatherapy and comfort massage were was statistically higher on the total hip arthroplasty group than on the total knee arthroplasty group. For example, 29\% $(n=218)$ responses indicated aromatherapy use day 2 post op for the total hip arthroplasty group, as compared with $22.6 \%(n=204)$ responses indicating aromatherapy use day 2 post op for the total knee arthroplasty group. Similarly, 36.3\% (n = 273) responses indicated aromatherapy use during hospitalization for the total hip arthroplasty group compared with $29.2 \%(n=264)$ responses indicating aromatherapy use during hospitalization for the total knee arthroplasty group. 
Table 9

Adjunct Therapy Use during Hospitalization after Total Hip or Total Knee Arthroplasty $(N=2005)^{a}$

\begin{tabular}{|c|c|c|c|c|c|c|}
\hline \multirow[b]{2}{*}{ Adjunct Therapy } & \multicolumn{2}{|c|}{ Total } & \multicolumn{2}{|c|}{$\begin{array}{c}\text { Total Knee } \\
\text { Arthroplasty }\end{array}$} & \multicolumn{2}{|c|}{$\begin{array}{c}\text { Total Hip } \\
\text { Arthroplasty }\end{array}$} \\
\hline & $n$ & $\%$ & $n$ & $\%$ & $n$ & $\%$ \\
\hline \multicolumn{7}{|l|}{ Day 2 Post Op } \\
\hline Acupuncture & 7 & 0.4 & 5 & 0.6 & 2 & 0.3 \\
\hline Aromatherapy & 422 & 25.5 & 204 & 22.6 & 218 & 29.0 \\
\hline Comfort massage & 188 & 11.3 & 87 & 9.6 & 101 & 13.4 \\
\hline Music therapy & 2 & 0.1 & 1 & 0.1 & 1 & 0.1 \\
\hline None & 1225 & 73.9 & 693 & 76.7 & 221 & 29.3 \\
\hline \multicolumn{7}{|c|}{ During Hospitalization } \\
\hline Acupuncture & 9 & 0.4 & 5 & 0.6 & 4 & 0.5 \\
\hline Aromatherapy & 537 & 26.8 & 264 & 29.2 & 273 & 36.3 \\
\hline Comfort massage & 340 & 17.0 & 168 & 18.6 & 172 & 22.8 \\
\hline Music therapy & 2 & 0.1 & 2 & 0.2 & 0 & 0.0 \\
\hline None & 1117 & 55.7 & 637 & 70.5 & 273 & 36.3 \\
\hline
\end{tabular}

Note. Frequencies and percentages presented only for "Yes" responses. Post Op = Post-operative. ${ }^{a}$ Frequencies and percentages refer to number of responses generated by 1657 participants; some participants used more than one adjunct therapy.

\section{Adjunct Therapy Use by Pain Status}

Adjunct therapy use of study participants day 2 post op and during hospitalization by pain status is presented in Table 9 and Figure 3. Chi-square analysis was conducted for the multiple response variables (adjunct therapy use day 2 post op and adjunct therapy use during hospitalization) and pain status. The results indicate the adjunct therapy used most often by patients reporting controlled pain on day 2 post op was comfort massage (n $=140,74.9 \%)$, followed by aromatherapy $(n=310,73.6 \%)$. The adjunct therapy used most often by patients reporting controlled pain during hospitalization is aromatherapy ( $n$ 
$=393,73.6 \%)$, followed by comfort massage $(n=247,73.1 \%)$. The use of acupuncture and music therapy was very infrequent, both on day 2 post op and during hospitalization.

Table 10

Adjunct Therapy Use during Hospitalization by Pain Status after Total Hip or Total Knee Arthroplasty $(N=1657)^{a}$

\begin{tabular}{lrrrrrc}
\hline & \multicolumn{7}{c}{ Uncontrolled Pain } & \multicolumn{2}{c}{ Controlled Pain } & & \\
\cline { 2 - 7 } Adjunct Therapy & $\boldsymbol{n}$ & $\boldsymbol{\%}$ & $\boldsymbol{n}$ & $\boldsymbol{\%}$ & $\chi^{2 \mathrm{~b}}$ & $\boldsymbol{P}^{\mathrm{b}}$ \\
\hline Day 2 Post Op & & & & & & \\
Acupuncture & 3 & 42.9 & 4 & 57.1 & -- & -- \\
Aromatherapy & 111 & 26.4 & 310 & 73.6 & 17.41 & $<.001$ \\
Comfort Massage & 47 & 25.1 & 140 & 74.9 & 8.54 & .003 \\
Music Therapy & 1 & 50.0 & 1 & 50.0 & -- & - \\
None & 450 & 37.5 & 751 & 62.5 & 15.38 & $<.001$ \\
During Hospitalization & & & & & & \\
Acupuncture & 4 & 44.4 & 5 & 55.6 & -- & -- \\
Aromatherapy & 141 & 26.4 & 393 & 73.6 & 24.13 & $<.001$ \\
Comfort Massage & 91 & 26.9 & 247 & 73.1 & 11.39 & .001 \\
Music Therapy & 1 & 50.0 & 1 & 50.0 & -- & - \\
None & 423 & 38.7 & 671 & 61.3 & 23.03 & $<.001$ \\
\hline
\end{tabular}

Note. Frequencies and percentages presented only for "Yes" responses. Post Op = Post-operative. aFrequencies and percentages refer to number of responses generated by 1657 participants; some participants used more than one adjunct therapy $y^{\mathrm{b}} \cdot \chi^{2}$ and $p$ refer to crosstabs between the adjunct therapy use (Yes, No) and pain status (controlled, uncontrolled). -- Only expected cell frequencies greater than 5 are reported.

Chi-square and Fisher's exact tests for associations were conducted between all adjunct therapies (acupuncture, aromatherapy, comfort massage, music therapy, none) and pain status (controlled, uncontrolled; Table 9). There was a statistically significant difference between pain status during hospitalization and aromatherapy use during hospitalization, $\chi^{2}(1)=24.13, p<.001$, Phi $=.122$ (small effect); comfort massage use during hospitalization, $\chi^{2}(1)=11.39, p=.001$, Phi $=.084$ (small effect); aromatherapy use day 2 post op, $\chi^{2}(1)=17.41, p<.001$, Phi $=.103$ (small effect); and comfort massage 
use day 2 post op, $\chi^{2}(1)=8.54, p=.003$, Phi $=.072$ (small effect). No statistically significant differences were found between patients’ pain status and other adjunct therapies such as acupuncture and music therapy.

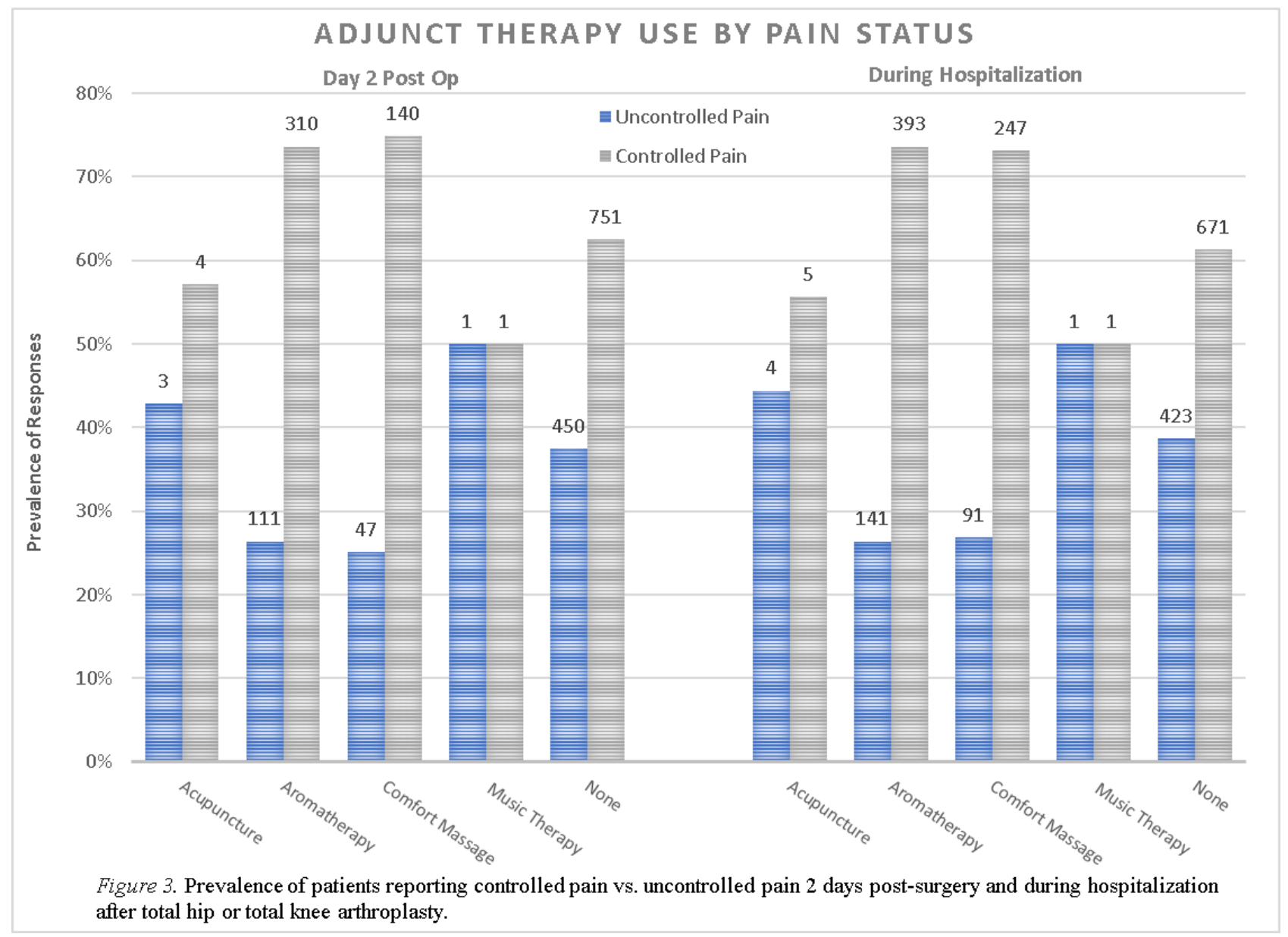

Figure 3. Adjunct therapy use by pain status. Prevalence of patients reporting controlled vs. uncontrolled pain during hospitalization after total hip or knee arthroplasty by type of adjunct therapy received. 


\section{CHAPTER V}

\section{DISCUSSION}

Management of post-surgical pain is difficult due to opioid tolerance as a result of high doses of opioids prior to surgery. Opioid administration is connected to many complications including respiratory depression, subsequent addiction, and death. The purpose of this study was to examine relationships among nursing interventions and pain status during hospitalization in orthopedic surgical patients. In this chapter study limitations and results are discussed.

Donabedian's theory of Structure, Process, and Outcome (SPO) informed the connections between the structure of four community hospitals' orthopedic units and culture of the nursing care delivery indicated by skill and balanced by the medical care and patient demographics. The process was directly related to nursing assessments and interventions. Patient outcomes varied as expected according to the structure and processes of nursing care delivery (Donabedian, 2003; Appendix B).

Good's (2004) nursing pain theory informed the study. Specifically, the theoretical underpinnings of the $3^{\text {rd }}$ Paradigm: Integrated Prescriptive Approaches informed the connections between multimodal interventions and attentive care as opioid sparing approaches to pain management (MY, 2015; Otten \& Dunn, 2011; Vaajoki, Pietilä, Kankkunen, \& Vehviläinen-Julkunen, 2012). This research focused on the cultural perspective of pain management (Good, 2004; Good \& Moore, 1996; McCaffrey \& Locsin, 2006; Montes-Sandoval, 1999; Peterson, 2013; Appendix C). 


\section{Synthesis of Findings for Research Aims}

The purpose of this study was to examine relationships among nursing

interventions and pain status during hospitalization in orthopedic surgical patients. The specific aims were (1) to describe the sociodemographic and clinical characteristics of a sample of orthopedic surgical patients after total hip or knee arthroplasty receiving services in one of four community hospitals in San Diego, California; (2) to examine relationships among the sociodemographic and clinical characteristics in terms of pain status (controlled vs. uncontrolled pain) for the study sample; and (3) to identify the factors that increase the likelihood of controlled pain during hospitalization for the study sample. All aims were met and the research findings are reviewed below.

\section{Sociodemographic and Clinical Characteristics of Study Population}

The sociodemographic and clinical characteristics of the 1,647 study participants overall and by type orthopedic surgery between March 1, 2016 and April 30, 2017 revealed $65.3 \%$ of patients reported control pain during hospitalization. Among the patients with uncontrolled pain (34.7\%: $n=566)$, slightly more patients in the total knee arthroplasty group had uncontrolled pain. In this sample, hospitals 1 through 3 performed between 506 and 572 surgeries; however, hospital 4 performed only 31 surgeries during the year. Close to $60 \%$ of all patients were female. The patients' average 1.09 MMEs for the whole hospitalization the rate was higher on day 2 when the effects of anesthesia were past. Patients' average time between NPAs during hospitalization was 124.05 minutes ( $\mathrm{SD}=43.23)$; this time was remarkably higher on day 2 post op $(\mathrm{M}=176.87$, $\mathrm{SD}=116.25)$. The large standard deviations values coupled with the large maximum times are likely to be a result of recording errors in the EHR. In the total knee 
arthroplasty and total hip arthroplasty surgical groups patients rarely reported severe pain. Severe pain was reported in $8.7 \%$ of total knee arthroplasties and $5.6 \%$ of total hip arthroplasties. These findings likely reflect the pain control priorities held by the interprofessional team of nurses, physicians, and pharmacists within these community hospitals with JC-certified orthopedic programs. (Hospital 4 performed only thirty-one surgeries indicating this hospital facility was not a JC-certified Total Joint Center.)

\section{Sociodemographic and Clinical Characteristics of Study Population by Pain Status}

A statistically significant difference was found between pain status during hospitalization and administration of a nerve block, the 1st half assessment, aromatherapy use during hospitalization, aromatherapy use and comfort massage on post op day 2. A statistically significant difference was not identified between patients reporting control versus uncontrolled pain for the variables of gender, veteran status, type of surgery, in relation time greater than 4 hours, and other adjunct therapies such as acupuncture and music therapy. Previous studies have identified gender as a significant variable in pain status (Fillingim, King, Ribeiro-Dasilva, Rahim-Williams, \& Riley, 2009). This study did not identify variation in pain control related to gender.

Pain control is reported to be challenging in the veteran patient population related to opioid tolerance developed after extended periods of chronic pain. This study did not identify variation in pain control related to veteran status; however, the accuracy of the data pertaining to veteran status may have contained recording errors due to lack of knowledge of patients' veteran status. The literature supports increased efforts to identify veterans treated in the community hospital setting to address the unique healthcare needs of this population (Collins et al., 2013; Koenig \& Seal; Thompson et al., 2009). 


\section{Relationships among Sociodemographic and Clinical Characteristics}

The relationships among the sociodemographic and clinical characteristics in terms of pain status (controlled vs. uncontrolled pain) for the study sample was described as a one-way between groups ANOVA conducted among all continuous variables and pain status during hospitalization (Table 4). The following continuous variables were evaluated: age, BMI at the time of surgery, daily MME during hospitalization, daily MME day 2 post op, renal failure, time between nursing pain assessments during hospitalization, time between nursing pain assessments day 2 post op. Pain status was categorized into controlled and uncontrolled pain.

Age. Age was statistically significantly different for patients with controlled and uncontrolled pain during hospitalization. Age was significantly higher for those with uncontrolled pain $(M=66.85, S D=10.34)$ than for those in the controlled pain group ( $M$ $=65.74, \mathrm{SD}=10.40)$. Increased age resulted in increased pain in the post op setting. Body Mass Index at the time of surgery was also statistically significantly different for patients with controlled and uncontrolled pain during hospitalization. Patients often delay joint replacement surgeries for more than a decade, waiting until alternatives to joint replacement are exhausted and patient age has advanced. This study indicates age is a significant factor for consideration in determining the optimal joint replacement surgery timing.

Basic metabolic index. This study found BMI was higher for those with uncontrolled pain $(M=31.88, S D=6.72)$ than for those with controlled pain $(M=30.16$, $\mathrm{SD}=5.96$ ). Higher BMI may be a result of debilitation prior to total joint replacement due to chronic pain. The literature has demonstrated patients who begin a program of 
exercise prior to surgery have improved outcomes (Brown et. al., 2014). This study indicates nursing interventions to decrease BMI prior to surgery increases the likelihood the patient will have controlled pain in the post op setting. In addition to age as a consideration when choosing to delay a needed joint replacement surgery, pain medications may cause unintended addictions. Unintended opioid addictions create additional difficulties for patients including decreased attention and energy often resulting in higher BMI at the time of surgery (Okie, 2010; Raffa \& Pergolizzi, 2014; Tormoehlen et al., 2011)

Time between nursing pain assessments. The average time between NPAs is a specific nursing care indicator demonstrating a construct within the control of the nurse (Carroll et al., 1999). Nurses may reduce variation in pain through improved assessment times. Increased time between nursing assessments increases the likelihood the patient will have uncontrolled pain (Jarzyna et al., 2011; Vargas-Schaffer \& Cogan, 2014). Time between nursing pain assessments during hospitalization was statistically significantly different for patients with controlled and uncontrolled pain during hospitalization. Contrary to the literature, the finding of this study indicated there was less time between the NPAs for patients with uncontrolled pain $(M=120.33$, SD = 39.25) than for those with controlled pain $(\mathrm{M}=124.89, \mathrm{SD}=41.69)$. Time between nursing pain assessment day 2 post op was statistically significantly different for patients with controlled and uncontrolled pain during hospitalization $($ Welch $F[1,1281]=19.402$, $\mathrm{p}<.001)$. Time between NPAs during hospitalization was lower for those with uncontrolled pain $(\mathrm{M}=$ $158.49, \mathrm{SD}=105.17)$ than for those with controlled pain $(\mathrm{M}=183.74, \mathrm{SD}=118.92)$. This finding reflects an increased responsiveness of the nurse for a patient in need of 
care. The results of this study indicated the nurses who were part of the Joint Commission Certified Total Joint program in the community hospital setting were responsive to their patients’ needs.

Morphine milligram equivalent. Morphine is considered the standard for opioids as the comparative measure for all opioids, which are also known as the most powerful analgesic for patients in pain (Vargas-Schaffer, 2010). However, MME during hospitalization and day 2 post op were not significantly associated with pain status during hospitalization; although MME on day 2 post op approached significance (Welch F $[1,1181]=3.693, p=.055)$, suggesting opioids may not be as important for patients in the controlled pain group, especially after day 2 post op. This study found MME did not contribute significantly to the predictive model for pain status (controlled or uncontrolled).

The following categorical and dichotomous level data were evaluated: nerve block, $1^{\text {st }}$ POSS day 2 post op, surgeon, and aromatherapy during hospitalization on the likelihood of patients reporting controlled pain during hospitalization following total hip or total knee arthroplasty.

Pasero Opioid Sedation Scale. Patients with POSS = 1 (awake and alert) were more likely to experience uncontrolled pain indicating a heightened wakefulness possibly a function of uncontrolled pain and possible under-medication. Patients with a POSS = 4 (somnolent minimal or no response to verbal and physical stimulation) were more likely to experience uncontrolled pain during hospitalization. This supports that a patient with the POSS $=4$ experiences over-sedation often, resulting in respiratory depression without a significant reduction in pain status. Patients who were assessed to have a baseline POSS 
$=2$ or 3 (Slightly drowsy, easily aroused or Frequently drowsy, arousable, drifts off to sleep during conversation) were more likely to experience controlled pain indicating adequate pain control; however, a POSS of 3 is unacceptable and the nurse must monitor respiratory status and sedation level closely until sedation level is less than 3 and respiratory status is satisfactory. Patients who were assessed to have a baseline POSS $=4$ (*Unacceptable; stop opioid; consider administering naloxone) were more likely to experience uncontrolled pain indicating the opioid level is excessive for this patient inducing respiratory depression while failing to provide adequate pain relief. Patients with surgeons who completed over 60 surgeries but less than 12 per month or 140 per year were more likely to experience uncontrolled pain during hospitalization.

Nerve block. A nerve block in patients undergoing a total knee arthroplasty, whether continuous or single injection, has been found to improve pain control and shorten rehabilitation times (Wegener et el., 2011). A patient receiving a nerve block post-surgery is more likely to have controlled pain and require fewer opioid medications; however, the nerve block is ordered and administered by the surgeon outside the control of the nurse. The nerve block was considered as an important variable related to the surgeon. The nerve block was considered as a covariate to identify the unique contribution to the patient's pain status. The nerve block varies greatly between surgeons. This study recommends further study to identify the appropriate method, timing, and approach for the surgeon's application of this technique. This procedure is outside of the control of the nurse.

Surgeons. Patients who were operated on by surgeons who completed between 60 and 89 arthroplasties during the length of this study were most likely to have uncontrolled 
pain. The influence of the specific surgeon was considered to ensure this variable was held as a constant; however, the surgeon data did not include specific individual characteristics. Number of surgeries at neighboring hospitals, university attended, unique pain management protocols (e.g. pre op, intra op, or post op nerve block), and surgeons' preferred patient choice (e.g., specialty in high BMI, age, sports medicine, and etc.) were not data available for consideration in this study.

Surgeon variability was not controlled due to the large number of surgeons in this study. Some statistical testing was not possible (e.g. crosstabs) due the researcher's computer memory limitations. Patients operated on by surgeons who completed between 60 and 89 arthroplasties during the length of the study were more likely to experience uncontrolled pain during hospitalization. This finding is likely because surgeons with less than 60 surgeries in this hospital system were likely specialists contracted for their vast experience and unique surgical techniques or surgeons with flourishing practices in a adjacent hospital system. Patients who selected surgeons with over 140 surgeries in this setting were significantly more likely to have controlled pain. The experience of the surgeon is usually a significant contributor as a predictor of pain status. Of note, surgeon 17 with 247 (14.9\%) surgeries had 187 (76.6\%) patients with controlled pain and 57 (23.4\%) patients with uncontrolled pain; yet, surgeon 9 with 216 (13.1\%, almost the same number of surgeries) had 107 (50.2\%) patients with controlled pain and 106 (49.8\%) with uncontrolled pain. This investigator recommends the hospital system independently analyze this data by surgeon for the purposes of process improvement and establishing best practice in this surgical population. 
Adjunct therapy use. Adjunct therapy use of all study participants on day 2 post op and during hospitalization is presented in Table 8. Out of 1,657 patients included in the study, 1,844 responses were generated with regards to adjunct therapy use day 2 post op (several patients reported using more than one adjunct therapy) and 2,005 responses during hospitalization. Out of the 1,844 responses generated on day 2 post op, the adjunct therapy selected most often was aromatherapy with $25.5 \%$ of responses $(n=422)$, followed by comfort massage with $11.3 \%$ of responses $(n=188)$. These results were slightly higher with patients' consideration of their whole hospitalization. Most of the aromatherapy was recorded on post op day 2, which is after the effects of anesthesia have dissipated. Out of the 2,005 responses generated during hospitalization, 26.8\% $(n=537)$ indicated they used aromatherapy. It is important to note aromatherapy and comfort massage use was higher in the total hip arthroplasty group than the total knee arthroplasty group. This study shows patients with controlled pain are using adjunct therapies more than those with uncontrolled pain during hospitalization; more information is needed regarding the reasons patients with uncontrolled pain are not using adjunct therapy. Pain level and lack of readily available adjunct therapies may present overwhelming barriers to patients with uncontrolled pain.

\section{Identification of Factors that Increase the Likelihood of Controlled Pain}

Predictors of controlled pain. Multiple studies have been conducted to determine the efficacy of specific medicine, pharmaceutical, physical therapy and nursing interventions for pain control following a total knee or a total hip arthroplasty; however, nurse-controlled predictors of pain status have not been studied specifically. A binomial logistic regression analysis identified the effects of BMI at the time of surgery, nerve 
block, first POSS day 2 post op, surgeon group, time between nurse pain assessments day 2 post op, and aromatherapy during hospitalization on the likelihood of patients reporting controlled pain during hospitalization following total hip or total knee arthroplasty (Table 7). The Nagelkerke's $\mathrm{R}^{2}$ of .124 indicated a predictor model with an overall prediction success of $68.2 \%$ ( $24.8 \%$ for patients with uncontrolled pain and $90.8 \%$ for patients with controlled pain during hospitalization). The Wald statistic indicated BMI, surgeon group, nerve block, first POSS day 2 post op, time between nursing pain assessments, and aromatherapy during hospitalization make significant contributions to the model. Those patients who received aromatherapy during hospitalization and a nerve block were more likely to have controlled pain, as were those with lower BMI. Patients with longer time between nurse pain assessments on day 2 post op were more likely to have their pain controlled during hospitalization, which may represent the appropriate responsiveness of the nurse to patients with uncontrolled pain compared to those with controlled pain in in this hospital setting.

The average time between NPAs is a specific nursing care indicator and demonstrates a construct that is within the control of the nurse. Pain expectation management (acceptable level of pain) has been identified as one of the most important contributors to unmanaged pain (Carroll et al., 1999). The investigator of this study expected that longer times between NPAs would result in an outcome of uncontrolled pain. However, patients who had longer times between nursing assessments were more likely to have controlled pain. This finding indicates the appropriate responsiveness of the nurse to patients' reports of uncontrolled pain. Patients who reported experiencing less pain appropriately had more time between assessments. The shorter time between 
assessments for patients with uncontrolled pain indicates the responsiveness of the nurse assisting patients in achieving their pain control goal in this hospital setting.

Adjunctive therapy was expected to be a challenge to include in the model for this study due to missing values, therapy type, and dosage. The data were analyzed as a dichotomous variable (yes/no) to determine if adjunctive therapy was provided to the patient and if it contributed to the overall model for pain control. Only one of the four hospitals consistently provided adjunctive therapy as part of the patient's pain control plan of care. Patients receiving aromatherapy demonstrated a statistical difference from patients who did not receive aromatherapy related to pain control. Patients who received aromatherapy were more likely to have their pain controlled.

Differences in pain may exist between the total hip and the total knee arthroplasty groups when compared in relation to pain variability.

\section{Limitations and Strengths of the Study}

A strength of this study was the large sample size and data available from four community hospitals over one year. The statistically significant data points may not be generalizable due to the unique characteristics of the hospitals, nurses, and surgeons in the organizations. Similarly, large community hospitals with the Cerner ${ }^{\circledR}$ EHR product may generate a report built with the same data points and expect the report would identify predictors of unmanaged pain in the specific acute care setting. Data collected from all modalities including the EHR may have intrinsic error built in due to recording errors and lack of interrater reliability. In addition, the researcher was previously unaware of a nerve block used for the total hip population. Because the data were from a secondary source, it 
was not possible to conduct chart reviews to determine if it was in error and investigate the finding for other unknown confounding factors.

Controlled pain as a concept was defined in terms of the patient's subjective report of pain to support clinical decision-making and allow the nurse to optimize patients' comfort and ability to function. Although the literature clearly supports the subjective report of pain as the most reliable indicator of pain, anxiety is often mistaken for pain (McCaffery, 1972; McCaffery \& Pasero, 1997; McWilliam \& Botwinski, 2010). Pain status, actual pain, and acceptable pain are all based on patient report. Another limitation of this study was in the dependent variable of "pain status" (controlled/uncontrolled) compared to the overall patient-reported median score to the patient's pain goal to determine status. Although some of the literature supports use of central tendency in the study of pain, further research is needed to support this methodology (Duncan \& Haigh, 2013). Patient satisfaction data and nurse surveys may help to confirm the reliability of this methodology in future studies.

\section{Implications for Practice}

Nurse-related pain management practices were studied to identify relationships between pain and nurse specific indicators (Carroll et al., 1999; Dowell et al., 2016; Pon et al., 2015). This study of pain status following a total knee or hip arthroplasty may be incorporated into standardized work for pain control. It is recommended that nursing practices to control pain consistently include adjunctive therapies, specifically aromatherapy, as part of standardized work to optimize pain management. Additionally, although many patients with musculoskeletal disorders may have resulting increased BMI, nurses’ pre op education should encourage patients to lower BMI, as it contributes 
significantly to pain control in the post op setting. Patients who had lower BMI and received aromatherapy during hospitalization and a nerve block were more likely to have controlled pain. Although the nerve block is a surgeon-controlled intervention, patient teaching and adjunctive therapy are nurse-controlled interventions. Nurses may also provide pain and sedation assessments to inform clinical judgments regarding opioid administration. Patients with longer time between nurse pain assessments on day 2 postsurgery were more likely to have controlled pain during their hospitalization. This finding supports the fact that nurses have responded to patients' reports of uncontrolled pain through increased attentiveness in this setting, resulting in improved outcomes.

Although it is not possible to standardize every aspect of nursing care, it is recommended that nurses consistently incorporate informed clinical decision-making, aromatherapy, and increased frequency of assessments for improved pain control. For the target state of standardized work to occur, all defining attributes or attributes of standardized work including specified content, specified sequence, specified timing, specified outcome, and dynamic continuous process improvement must be present. Standardized work is not an unmindful, set way of working, but rather a mindful, dynamic state in which all nursing and healthcare quality problems may be addressed.

\section{Implications for Education}

Therapeutic patient education is central to multimodal pain management. Nurses provide education to assist patients and their families when managing treatments and avoiding preventable complications, while maintaining or improving quality of life (Vargas-Schaffer \& Cogan, 2014). Although many patients with musculoskeletal disorders may have resulting increased BMI, this study recommends nurses' pre op 
education encourages patients to lower BMI, as it contributes significantly to pain control in the post op setting. Nurses provide care for patients while educating them and their families for self-care after their discharge from the hospital setting. It is recommended that nursing practices to control pain consistently include adjunctive therapies, specifically aromatherapy, as part of standardized work to optimize pain management. Patient and family education mirrors the care the nurse provides in the hospital setting. Variation in nursing practices for pain management must be evaluated to facilitate the development of informed standardized nursing work, patient and family education, and as part of academic preparation for all levels of nursing practice. Nurses are well positioned to lead a new paradigm in pain management through evidence-based education regarding opioid-sparing approaches to pain control.

\section{Implications for Research}

For purposes of this study, data were extracted from the EHR. While EHR data collected by nurses from standardized fields was assumed to correspond to the reality of the clinical status of the patient, errors are inherent in the records as they are in all recording modalities. Pain status is data recorded by nurses in the EHR. This data provided the opportunity to enhance patient care through detailed tracking of clinical status and proved to be useful for clinical research. Pain Status is a product of two standardized EHR data fields: actual pain and acceptable level of pain. Using EHR data in clinical research presents several challenges due to lack of standardized data fields providing research relevant and analysis ready data. Expansion of the standardized fields available to clinicians is important to advance nursing research. In addition, busy nursing workloads and other distractions may contribute to errors in nursing data recording. 
Reusing EHR data designed for clinical practice has been questioned for use in clinical trials and clinical research.

Increased clinical research using the EHR will advance the commitment to ensuring EHR data reliability and validity. Clinicians and researchers committed to ensuring the integrity of the data and advancing validation methodology as part of the clinical workflow support optimization of both clinical practice and research. Accurate EHR data collected by clinicians is required as a reliable and valid source of information for clinical decision-making, quality improvements, research, and policy. Improved nursing outcomes are informed by research using EHR data that accurately corresponds to the reality of the clinical status of the patient (Cowie et al., 2017; Thoroddsen et al., 2013). Nurses are well positioned to lead a new paradigm in pain management through research regarding opioid-sparing approaches to pain control.

\section{Implications for Health Policy}

In 2016, the United States had $4.6 \%$ of the world population, yet consumed $80 \%$ of the opioid supply and 99\% of the hydrocodone supply in the world (Pon et al., 2016). The reasons for the national opioid epidemic are complex; however, decreasing opioid availability and use through political mandates, for example, Washington State Legislature’s ESHB 2876 would likely have immediate and profound effects in pain management while substantially decreasing unintended consequences of opioid-related injury and death. Because only the United States consumes this amount of opioid, a comparison to countries with substantially less consumption would be informative to determine if pain status is uncontrolled. The findings of this study suggest pain may not be the most influential factor for high MME. 
Hospital nursing care sets the trajectory for patients managing their pain at home; consequently, hospital nurses are empowered to practice using a multimodal approach backed by strong state mandates to ensure interprofessional collaboration between Surgeons, pharmacists, and nurses. This study found MME was not significant in predicting uncontrolled pain. Opioid-sparing and nurse-controlled approaches to pain control have shown efficacy. Policies supporting adjunct therapies as the first choice for pain status improvements are supported by these findings. Since the early 1990s, the WHO analgesic ladder continues to recommend adjunct therapy as the first choice for pain control. Opioids were recommended for use when all other less potent interventions were already in place for the patient. Stricter policies may be useful to ensure adherence to these evidence-based guidelines supported by the findings of this study.

\section{Summary}

Patients' experiences of pain are subjective and multifaceted. It is currently not possible to objectively measure pain intensity, supporting the widespread belief the patient's report of pain is the most reliable measure (McCaffery \& Pasero, 1997; Pasero et al., 2016). The operational definition is the subjective report of actual pain as measured by a clinically appropriate pain scale compared to the patient's pain goals negotiated with the nurse as the acceptable level of pain. Only a portion of controlled pain may be measured by pain intensity rating scales, so a more comprehensive assessment is recommended. Pain in the hospitalized patient requires the nurse to make a judgment regarding pain control. It is a widely-held belief nursing care for the hospitalized patient that provides safe and effective pain management results in controlled pain. Variables may be extracted from the EHR for quantitative measurement in research; however, EHR 
data collected by clinicians must be an accurate, reliable and valid source of information for research. Currently, the generalizability of the EHR study may be called into question. Accurate EHR data must be ensured to inform clinical workflows and clinical research. Standardized fields designed by clinicians and researchers will allow the data to accurately correspond to the reality of the clinical status of the patient, improving reliability of the EHR and the validity of EHR data.

\section{Conclusion}

The strongest predictors of pain status were aromatherapy during hospitalization, nerve block, BMI, and time between NPAs during hospitalization. The predictors reliably predicted pain status (patients who had controlled from those who had uncontrolled pain during hospitalization). The predictor model with an overall prediction success of $68.6 \%$ indicates important variables that are within the control of the nurse. Pre-operatively, the nurse may collaborate with the patient to lower the patient's BMI for improved pain status outcomes. Nurses may collaborate with the interprofessional team to advocate for earlier interventions in order to avoid arthroplasties in patients with advanced age. Nurses may teach their patients the importance of a multimodal approach to pain control beginning with adjunct treatments, especially aromatherapy, that may be continued after the patient is discharged home. This study found it is important to know what contributes to this model (e.g., surgeon experience, age, BMI, time between nursing pain assessments, aromatherapy) and what does not significantly contribute to this model (e.g., MME). These findings support an opioidsparing approach to pain management for reasons of patient safety and efficacy for pain control. Future studies are needed to identify the most effective opioid-sparing approaches and adjunct therapies specifically designed to control pain in the post op setting. 


\section{References}

Allen, D. (2004). Ethnomethodological insights into insider-outsider relationships in nursing ethnographies of healthcare settings. Nursing Inquiry, 11(1), 14-24.

Allen, D. (2014). Lost in translation? "Evidence” and the articulation of institutional logics in integrated care pathways: From positive to negative boundary object? Sociology of Health and Illness, 36(6), 807-822. doi:10.1111/1467-9566.12111

American Society for Pain Management Nursing [ASPMN], 2009 Evidence-based guideline for sedation and respiratory monitoring during opioid administration for pain management. Lenexa, KS: ASPMN.

ASPMN American Society for Pain Management Nursing [ASPMN], 2018 Core curriculum for pain management nursing (Third ed.): Elsevier.

Andrews, M. (2011, March 29). Some doctors require patients to sign contracts get opioid painkillers. The Washington Post. Retrieved from https://www.washingtonpost.com/national/health/some-doctors-require-patientsto-sign-contracts-get-opioid-painkillers/2011/03/29/AF7D31dC_story.html

Bandyopadhyay, R., Dihn, T., He, N., Morimune, J., Nguyen, B., Pollack, M., . . . Ferrone, M. (2016). A cross-sectional analysis of changes in the current system as perceived by San Francisco Bay Area community pharmacists. Paper presented at the West Coast Pharmacy Exchange, San Francisco.

Barnas, K. (2011). ThedaCare's business performance system: sustaining continuous daily improvement through hospital management in a lean environment. Joint Commission Journal on Quality \& Patient Safety, 37(9), 387-399. 
Begley, C., Elliott, N., Lalor, J., Coyne, I., Higgins, A., \& Comiskey, C. M. (2013).

Differences between clinical specialist and advanced practitioner clinical practice, leadership, and research roles, responsibilities, and perceived outcomes (the SCAPE study). Journal of Advanced Nursing, 69(6), 1323-1337 1315p. doi:10.1111/j.1365-2648.2012.06124.x

Ben-Tovim, D. I., Bassham, J. E., Bolch, D., Martin, M. A., Dougherty, M., \& Szwarcbord, M. (2007). Lean thinking across a hospital: Redesigning care at the Flinders Medical Centre. Australian Health Review, 31(1), 10-15.

Berry, P. H., \& Dahl, J. L. (2000a). Making pain assessment and management a healthcare system priority through the new JCAHO pain standards. Journal of Pharmaceutical Care in Pain and Symptom Control, 8(2), 5-20.

Berry, P. H., \& Dahl, J. L. (2000b). The new JCAHO pain standards: Implications for pain management nurses. Pain Management Nursing, 1(1), 3-12.

Box, G. E. P., \& Tidwell, P. W. (1962). Transformation of the independent variables. Technometrics, 4(4), 531-550. doi:10.1080/00401706.1962.10490038

Brown, K., Loprinzi, P. D., Brosky, J. A., \& Topp, R. (2014). Prehabilitation influences exercise-related psychological constructs such as self-efficacy and outcome expectations to exercise. The Journal of Strength \& Conditioning Research, 28(1), 201-209. doi:10.1519/JSC.0b013e318295614a

Buss, H. E., \& Melderis, K. (2002). PACU pain management algorithm. Journal of Perianesthesia Nursing, 17(1), 11-20.

Cahana, A., Dansie, E. J., Theodore, B. R., Wilson, H. D., \& Turk, D. C. (2013). Redesigning delivery of opioids to optimize pain management, improve 
outcomes, and contain costs. Pain Medicine, 14(1), 36-42.

doi:10.1111/pme.12013

Carroll, K. C., Atkins, P. J., Herold, G. R., Mlcek, C. A., Shively, M., Clopton, P., \&

Glaser, D. N. (1999). Pain assessment and management in critically ill postoperative and trauma patients: A multisite study. American Journal of Critical Care, 8(2), 105-117.

Cassel, C. K., \& Saunders, R. S. (2014). Engineering a better health care system: a report from the President's Council of Advisors on Science and Technology. JAMA, 312(8), 787-788.

Chassin, M. R., \& Loeb, J. M. (2013). High-Reliability Health Care: Getting There from Here. Milbank Quarterly, 91(3), 459-490 432p. doi:10.1111/1468-0009.12023

Ching, J. M., Williams, B. L., Idemoto, L. M., \& Blackmore, C. C. (2014). Using lean “automation with a human touch" to improve medication safety: A step closer to the “perfect dose.” Joint Commission Journal on Quality \& Patient Safety, 40(8), 341-350.

Choinière, M., \& Watt-Watson, J. (2014). Persistent postoperative nonanginal pain after cardiac surgery. CMAJ, 186(11), 855. doi:10.1503/cmaj.114-0057

Chou, R., Gordon, D. B., de Leon-Casasola, O. A., Rosenberg, J. M., Bickler, S., Brennan, T., .. . Thirlby, R. (2016). Management of Postoperative Pain: A Clinical Practice Guideline From the American Pain Society, the American Society of Regional Anesthesia and Pain Medicine, and the American Society of Anesthesiologists' Committee on Regional Anesthesia, Executive Committee, and 
Administrative Council. Journal of Pain, 17(2), 131-157 127p.

doi:10.1016/j.jpain.2015.12.008

Collins, E., Wilmoth, M., \& Schwartz, L. (2013). “Have you ever served in the military?” Campaign in partnership with the Joining Forces initiative. Nursing Outlook, 61(5), 375-376.

Control. (2018). In Merriam-Webster’s online diccionary. Retrieved from: https://www.merriam-webster.com/dictionary/control

Cowie, M. R., Blomster, J. I., Curtis, L. H., Duclaux, S., Ford, I., Fritz, F., . . Leenay, M. (2017). Electronic health records to facilitate clinical research. Clinical Research in Cardiology, 106(1), 1-9.

Curtiss, C. P. (2001). JCAHO: Meeting the standards for pain management. Orthopaedic Nursing, 20(2), 27-44.

Cveykus, R., \& Carter, E. (2006). Fix the process, not the people. Strategic Finance, 88(1), 27-33.

Devine, E. C., Bevsek, S. A., Brubakken, K., Johnson, B. P., Ryan, P., Sliefert, M. K., \& Rodgers, B. (1999). AHCPR clinical practice guideline on surgical pain management: Adoption and outcomes. Research in Nursing and Health, 22(2), 119-130.

Donabedian, A. (2002). An introduction to quality assurance in health care. New York, NY: Oxford University Press.

Dowell, D., Haegerich, T. M., \& Chou, R. (2016). CDC guideline for prescribing opioids for chronic pain: United States, 2016. MMWR. Recommendations and Reports: mortality and morbidity weekly report, 65(1), 1-49. doi:10.15585/mmwr.rr6501e1 
Drake, D. A., Luna, M., Georges, J. M., \& Steege, L. M. B. (2012). Hospital nurse force theory: A perspective of nurse fatigue and patient harm. Advances in Nursing Science, 35(4), 305-314. doi:10.1097/ANS.0b013e318271d104

Duncan, F., \& Haigh, C. (2013). Measuring and improving the quality of postoperative epidural analgesia for major abdominal surgery using statistical process control charts. Journal of Clinical Nursing, 22(19-20), 2748-2757.

Dynamic. M.-W. (2015). Retrieved from http://www.merriamwebster.com/dictionary/dynamic

Eisenhauer, L. A., Hurley, A. C., \& Dolan, N. (2007). Nurses' reported thinking during medication administration. Journal of Nursing Scholarship, 39(1), 82-87. doi:10.1111/j.1547-5069.2007.00148.x

Elkins, C. (2016, March 17). CDC announces official guidelines for opioid prescriptions. Retrieved from https://www.drugrehab.com/2016/03/17/cdc-announcesguidelines-for-opioid-prescriptions/

Fillingim, R. B., King, C. D., Ribeiro-Dasilva, M. C., Rahim-Williams, B., \& Riley, J. L. (2009). Sex, gender, and pain: A review of recent clinical and experimental findings. The Journal of Pain, 10(5), 447-485.

Fishman, S. M., Young, H. M., Lucas Arwood, E., Chou, R., Herr, K., Murinson, B. B., . . Stevens, B. J. (2013). Core competencies for pain management: Results of an interprofessional consensus summit. Pain Medicine, 14(7), 971-981.

Franklin, G., Sabel, J., Jones, C. M., Mai, J., Baumgartner, C., Banta-Green, C. J., ...Tauben DJ. (2015). A comprehensive approach to address the prescription 
opioid epidemic in Washington State: Milestones and lessons learned. American Journal of Public Health, 105(3), 463-469. doi:10.2105/AJPH.2014.302367

Gilbreth, F. B. (1911). Motion study: A method for increasing the efficiency of the workman. New York: D. Van Nostrand Company.

Gilbreth, L. M. (1914). The psychology of management: The functions of the mind in determining, teaching, and installing the methods of least waste. New York: Sturgis and Walton Company.

Good, M. (2004). Pain: A balance between analgesia and side effects. In S. J. \& T. S. Bredow (Eds.), Middle range theories application to nursing research ( $2^{\text {nd }}$ ed.), pp. 63-81. Philadelphia, PA: Wolters Kluwer Health.

Good, M., \& Moore, S. M. (1996). Clinical practice guidelines as a new source of midlerange theory: Focus on acute pain. Nursing Outlook, 44(2), 74-79. doi:10.1016/S0029-6554(96)80053-4

Graban, M. (2011). Lean hospitals: Improving quality, patient safety, and employee engagement ( $2^{\text {nd }}$ ed.). Boca Raton, FL: CRC.

Hawker, G. A., Mian, S., Kendzerska, T., \& French, M. (2011). Measures of adult pain: Visual Analog Scale for Pain (VAS Pain), Numeric Rating Scale for Pain (NRS Pain), McGill Pain Questionnaire (MPQ), Short-Form McGill Pain Questionnaire (SF-MPQ), Chronic Pain Grade Scale (CPGS), Short Form-36 Bodily Pain Scale (SF-36 BPS), and Measure of Intermittent and Constant Osteoarthritis Pain (ICOAP). Arthritis Care \& Research, 63(Suppl 11), S240-252. doi:10.1002/acr.20543 
Hayes, K. \& Gordon, D. B. (2015). Delivering quality pain management: The challenge for nurses. AORN Journal, 101(3), 328-34. doi: 10.1016/j.aorn.2014.11.019

Institute of Medicine (US) Committee on the Robert Wood Johnson Foundation Initiative on the Future of Nursing, at the Institute of Medicine. The Future of Nursing: Leading Change, Advancing Health. Washington, DC: National Academies Press. Available from: https://www.ncbi.nlm.nih.gov/books/NBK209880/ doi:10.17226/12956

Jarzyna, D., Jungquist, C. R., Pasero, C., Willens, J. S., Nisbet, A., Oakes, L., . . . Polomano, R. C. (2011). American Society for Pain Management Nursing guidelines on monitoring for opioid-induced sedation and respiratory depression. Pain Management Nursing, 12(3), 118-145. doi: 10.1016/j.pmn.2011.06.008

Jones, C. M. (2013). Heroin use and heroin use risk behaviors among nonmedical users of prescription opioid pain relievers-United States, 2002-2004 and 2008-2010. Drug and Alcohol Dependence, 132(1), 95-100.

Kalisch, B. J. (2015). Errors of ommission: how missed nursing care imperils patients. Silver Spring, MD: American Nurses Association.

Kim, C. S., Spahlinger, D. A., Kin, J. M., Coffey, R. J., \& Billi, J. E. (2009). Implementation of Lean thinking: One health system's journey. Joint Commission Journal on Quality \& Patient Safety, 35(8), 406-413.

Kobelt, P., Burke, K., \& Renker, P. (2014). Evaluation of a standardized sedation assessment for opioid administration in the post anesthesia care unit. Pain Management Nursing, 15(3), 672-681. doi:http://dx.doi.org/10.1016/j.pmn.2013.11.002 
Koenig, C. J., Maguen, S., Monroy, J. D., Mayott, L., \& Seal, K. H. (2014). Facilitating culture-centered communication between health care providers and veterans transitioning from military deployment to civilian life. Patient Education and Counseling, 95(3), 414-420. Doi:10.1016/j.pec.2014.03.016

Kohn, L. T., Corrigan, J. M., \& Donaldson, M. S. (2000). To err is human: Building a safer health system. Washington DC: National Academy Press.

Koppel, R., Wetterneck, T., Telles, J. L., \& Karsh, B. (2008). Workarounds to barcode medication administration systems: Their occurrences, causes, and threats to patient safety. Journal of the American Medical Informatics Association, 15(4), 408-423.

Kwan, S., Daniels, M., Ryan, L., \& Fields, W. (2015). Creating a standardized process to meet core measure compliance. Journal of Nursing Care Quality, 30(4), 331-336. doi:10.1097/ncq.0000000000000148

Labarere, J., Bosson, J., Brion, J., Fabre, M., Imbert, B., Carpentier, P., \& Pernod, G. (2004). Validation of a clinical guideline on prevention of venous thromboembolism in medical inpatients: A before-and-after study with systematic ultrasound examination. Journal of Internal Medicine, 256(4), 338-348 311p.

Leavitt, S. B. (2011, September 1). Rules hurt patients with pain in Washington state. Retrieved from tp://updates.pain-topics.org/2011/09/rules-hurt-patients-with-painin.html?pfstyle=wp

Lim, Y. C., Yobas, P., \& Chen, H. C. (2014). Efficacy of relaxation intervention on pain, self-efficacy, and stress-related variables in patients following total knee 
replacement surgery. Pain Management Nursing, 15(4), 888-896.

doi:http://dx.doi.org/10.1016/j.pmn.2014.02.001

Lombardi, A. V., Jr., Berend, K. R., \& Adams, J. B. (2010). A rapid recovery program: Early home and pain free. Orthopedics, 33(9), 656-656. doi:10.3928/0147744720100722-23

Mannon, M. (2014). Lean healthcare and quality management: The experience of ThedaCare. Quality Management Journal, 21(1), 7-10. .

Matthews, E., \& Malcolm, C. (2007). Nurses' knowledge and attitudes in pain management practice. British Journal of Nursing, 16(3), 174-179. doi:10.12968/bjon.2007.16.3.22972

Mathiesen, O., Dahl, B., Thomsen, B., Kitter, B., Sonne, N., Dahl, J., \& Kehlet, H. (2013). A comprehensive multimodal pain treatment reduces opioid consumption after multilevel spine surgery. European Spine Journal, 22(9), 2089-2096. doi:10.1007/s00586-013-2826-1

McCaffery, M. (1998). Pain control. Is laughter the best medicine? AJN American Journal of Nursing, 98(12), 12-12.

McCaffery, M., \& Pasero, C. L. (1997). Pain ratings: The fifth vital sign. The American Journal of Nursing, 97(2), 15-16.

McCaffrey, M. (1972). Nursing management of the patient with pain. Philadelphia, PA: J. B. Lippincott.

McCaffrey, R., \& Locsin, R. (2006). The effect of music on pain and acute confusion in older adults undergoing hip and knee surgery. Holistic Nursing Practice, 20, 218224. doi:10.1097/00004650-200609000-00002 
McWilliam, P., \& Botwinski, C. (2010). Developing a successful nursing objective structured clinical examination. Journal of Nursing Education, 49(1), 36-41. doi:10.3928/01484834-20090915-01

Molon, D. (2014). Feeling safe during an inpatient hospitalization. Journal of Advanced Nursing, 70(8).

Montes-Sandoval, L. (1999). An analysis of the concept of pain. Journal of Advanced Nursing, 29(4), 935-941. doi:10.1046/j.1365-2648.1999.00971.x

MY, N. (2015). The effectiveness of music therapy for post-pperative pain control among total knee replacement patients. Medicine \& Health, 10(1), 66-79.

Neven, D. E., Sabel, J. C., Howell, D. N., \& Carlisle, R. J. (2012). The development of the Washington state emergency department opioid prescribing guidelines. Journal of Medical Toxicology, 1-7.

New JCAHO standards. (2000). RN, 63(5), 24hf28-24hf10 22p.

Nielsen, S., Degenhardt, L., Hoban, B., \& Gisev, N. (2016). A synthesis of oral morphine equivalents (OME) for opioid utilisation studies. Pharmacoepidemiology and Drug Safety, 25(6), 733-737.

Nisbet, A. T., \& Mooney-Cotter, F. (2009). Comparsion of selected sedation scales for reporting opioid-induced sedation assessment. Pain Management Nursing, 10(3), 154-164. doi:10.1016/j.pmn.2009.03.001

Okie, S. (2010). A flood of opioids, a rising tide of deaths. New England Journal of Medicine, 363(21), 1981-1985.

Otten, C., \& Dunn, K. (2011). Mulitmodal analgesia for postoperative total knee arthroplasty. Orthopaedic Nursing, 30(6), 373-380. 
doi:10.1097/NOR.0b013e318237108a

Pain Management and Schedule II Drug Prescriptions Assembly Bill 2017 (CA) No. 1048 (USA). Retrieved from https://leginfo.legislature.ca.gov/faces

Pasero, C. L., \& McCaffery, M. (1998). Pain control. Is laughter the best medicine? AJN: American Journal of Nursing, 98(12), 12.

Pasero, C., Quinlan-Colwell, A., Rae, D., Broglio, K., \& Drew, D. (2016). American Society for Pain Management nursing position statement: Prescribing and administering opioid doses based solely on pain intensity. Pain Management Nursing, 17(3), 170-180. doi:10.1016/j.pmn.2016.03.001

Pasero, C., Quinn T., Portenoy R., McCaffery M., \& Rizos A. (2011). Opioid analgesics. In C. Pasero and M. McCaffery (eds.). Pain Assessment and Pharmacologic Management (pp. 277-622). St. Louis, MO: Mosby/Elsevier.

Pesut, B., \& McDonald, H. (2007). Connecting philosophy and practice: Implications of two philosophic approaches to pain for nurses' expert clinical decision making. Nursing Philosophy, 8(4), 256-263. doi:10.1111/j.1466-769X.2007.00322.x

Peterson, S. J., \& Bredow, T. S. (2013). Middle range theories: Application to nursing research ( $3^{\text {rd }}$ ed.). Philadelphia, PA: Wolters Kluwer Health.

Pham, P. C., Khaing, K., Sievers, T. M., Pham, P. M., Miller, J. M., Pham, S. V., . . . Pham, P. T. (2017). 2017 update on pain management in patients with chronic kidney disease. Clinical Kidney Journal, 10(5), 688-697.

Pon, D., Awuah, K., Curi, D., Okyere, E., \& Stern, C. S. (2015). Combating an epidemic of prescription opioid abuse. Journal of the California Dental Association, 43(11), 673-678. 
Pon, D., Awuah, K., Curi, D., Okyere, E., \& Stern, C. S. (2016). Combating an epidemic of prescription opioid abuse. California pharmacist (Winter), 23-30.

Raffa, R. B., \& Pergolizzi, J. V. Jr. (2014). A modern analgesics pain 'pyramid'. Journal of Clinical Pharmacy and Therapeutics, 39(1), 4-6. doi:10.1111/jcpt.12110.

RN news watch. (1999). $R N$, 62(11), 10-11.

Ravitch, S. M., \& Riggan, M. (2012). Reason \& rigor: How conceptual frameworks guide research. London: Sage.

Roden, A., \& Sturman. E. (2009). Assessment and management of patients with woundrelated pain. Nursing Standard, 23(45), 53-54, 56, 58.

doi:10.7748/ns2009.07.23.45.53.c7116

Roth, C. P., Lim, Y.-W., Pevnick, J. M., Asch, S. M., \& McGlynn, E. A. (2009). The challenge of measuring quality of care from the electronic health record. American Journal of Medical Quality, 24(5), 385-394.

Rother, M. (2010). Toyota Kata: Managing people for improvement, adaptive nurse, and superior results. New York: McGraw-Hill Education.

Sandlin, D. (2000). The new joint commission accrediation of healthcare organizations' requirements for pain assessment and treatment: A pain in the assessment? Journal of Perianesthesia Nursing, 15(3), 182-184. doi: http://dx.doi.org/10.1053/jpan.2000.7511

Sloan, T., Fitzgerald, A., Hayes, K. J., Radnor, Z., Robinson, S., \& Sohal, A. (2014). Lean in healthcare: History and recent developments. Journal of Health Organization and Management, 28(2), 130-134. 
Soto, R., \& Yaldou, B. (2015). The Michigan opioid safety score (MOSS): A patient safety and nurse empowerment tool. Journal of Perianesthesia Nursing, 30(3), 196-200 195p. doi:10.1016/j.jopan.2015.01.009

Spear, S. J. (1999). The Toyota production system: An example of managing complex social/technical systems. 5 rules for designing, operating, and improving activities, activity-connections, and flow-paths. Retrieved from https://www.researchgate.net/publication/35485567_The_Toyota_production_syst em_an_example_of_managing_complex_socialteaching_systems_5_rules_for_de signing_operating_and_improving_activities_activity-connections_and_flowpaths

Spear, S. J., \& Schmidhofer, M. (2005). Ambiguity and workarounds as contributors to medical error. Annals of Internal Medicine, 142(8), 627-630.

Spear, S., \& Bowen, H. K. (1999). Decoding the DNA of the Toyota Production System. Harvard Business Review, 77(5), 96-106.

Standard. Merriam-Webster, Dictionary. (2015). Retrieved from http://www.merriamwebster.com/dictionary/standard

Stratton Hill Jr, C. (1996). Government regulatory influences on opioid prescribing and their impact on the treatment of pain of nonmalignant origin. Journal of Pain and Symptom Management, 11(5), 287-298. doi: http://dx.doi.org/10.1016/08853924(95)00203-0

Sullivan, M., Tanzer, M., Stanish, W., Fallaha, M., Keefe, F. J., Simmonds, M., \& Dunbar, M. (2009). Psychological determinants of problematic outcomes following total knee arthroplasty. Pain, 143(1-2), 123-129. 
Swensen, S. J., Dilling, J. A., McCarty, P. M., Bolton, J. U., \& Harper, C. M. (2013). The business case for healthcare quality improvement. Journal of Patient Safety, 9(1), $44-52$.

Taylor, F. W. (1914). The principles of scientific management. New York: Harper \& Brothers.

The Joint Commission (2012). The Joint Commission Sentinel Event Alert, Issue 49. Retrieved from http://www.jointcommission.org/assets/1/18/SEA_49_opioids_8_2_12_final.pdf

Thompson, D. N., Wolf, G. A., \& Spear, S. J. (2003). Driving improvement in patient care: Lessons from Toyota. Journal of Nursing Administration, 33(11), 585-595.

Thompson, J. M., Chiasson, R., Loisel, P., Besemann, L. C. M., \& Pranger, T. (2009). A sailor's pain: Veterans' musculoskeletal disorders, chronic pain, and disability. Canadian Family Physician, 55(11), 1085-1088.

Thoroddsen, A., Sigurjónsdóttir, G., Ehnfors, M., \& Ehrenberg, A. (2013). Accuracy, completeness and comprehensiveness of information on pressure ulcers recorded in the patient record. Scandinavian Journal of Caring Sciences, 27(1), 84-91. doi:10.1111/j.1471-6712.2012.01004.x

Tormoehlen, L. M., Mowry, J. B., Bodle, J. D., \& Rusyniak, D. E. (2011). Increased adolescent opiod use and complications reported to a poison control center following the 2000 JCAHO pain initiative. Clinical Toxicology, 49(6), 492-498. doi:10.3109/15563650.2011.587819

Toussaint, J. S., \& Berry, L. L. (2013). Leadership lessons from lean. Trustee, 66(10), 2124. 
Toussaint, J. S., \& Berry, L. L. (2013). The promise of Lean in health care. Mayo Clinic Proceedings, 88(1), 74-82. doi:10.1016/j.mayocp.2012.07.025

U. S. Food and Drug Administration. (2016). FDA announces enhanced warnings for immediate-release opioid pain medications related to risks of misuse, abuse, addiction, overdose and death. U.S. Department of Health and Human Services. Retrieved from http://www.fda.gov/NewsEvents/Newsroom/PressAnnouncements

Vaajoki, A., Pietilä, A. M., Kankkunen, P., \&Vehviläinen-Julkunen, K. (2012). Effects of listening to music on pain intensity and pain distress after surgery: An intervention. Journal of Clinical Nursing, 21(5-6), 708-717. doi:10.1111/j.13652702.2011.03829.x

VandenBosch, T. M. (2002). Relationships among patient self-report of pain intensity, pain duration and satisfaction with pain management at a community teaching hospital. (Doctoral dissertation). Retrieved from http://search.ebscohost.com/login.aspx?direct=true\&db=rzh\&AN=109876612\&sit $\mathrm{e}=$ ehost-live Available from EBSCOhost rzh database.

Vargas-Schaffer, G. (2010). Is the WHO analgesic ladder still valid?: Twenty-four years of experience. Canadian Family Physician, 56(6), 514-517. Retrieved from https://www.ncbi.nlm.nih.gov/pmc/articles/PMC2902929/

Vargas-Schaffer, G., \& Cogan, J. (2014). Patient therapeutic education: Placing the patient at the centre of the WHO analgesic ladder. Canadian Family Physician, 60(3), 235-241.

Ventura, M. J. (1999). RN, 62(11), 10-10. 
Walker, L., \& Avant, K. (2011). Strategies for theory construction in nursing (5 $5^{\text {th }}$ ed.). New York: Pearson.

Waltz, C. F., Strickland, O.L., \& Lenz, E.R. (2017). Measurement in nursing and health research. ( $5^{\text {th }}$ ed.). New York: Springer.

Wegener, J. T., van Ooij, B., van Dijk, C. N., Hollmann, M. W., Preckel, B., \& Stevens, M. F. (2011). Value of single-injection or continuous sciatic nerve block in addition to a continuous femoral nerve block in patients undergoing total knee arthroplasty: A prospective, randomized, controlled trial. Regional Anesthesia and Pain Medicine, 36(5), 481-488.

Witzel, M., \& Warner, M. (2013). The Oxford handbook of management theorists. London, England: MPD Books Group, Bodmin and King's Lynn.

Womack, J. (2005). Problems with creativity. Manufacturing Engineer, 84(3), 5.

Womack, J. (2006). Counting the cost of misinformation. Manufacturing Engineer, 85(6), 7. doi:10.1049/me:20060608

Womack, J. P., \& Jones, D. T. (1996). Beyond Toyota: How to root out waste and pursue perfection. Harvard Business Review, 74(5), 140-158.

Womack, J. P., \& Jones, D. T. (2010). Lean thinking: Banish waste and create wealth in your corporation. New York: Simon and Schuster.

Womack, J. P., Jones, D. T., \& Cahoon, R. B. (2006). Lean thinking: Banish waste and create wealth in your corporation. Armed Forces Comptroller, 51(3), 43-45.

Wu, C. L., \& Raja, S. N. (2011). Treatment of acute postoperative pain. Lancet, 377(9784), 2215-2225. doi:10.1016/S0140-6736(11)60245-6 


\section{Appendix A}

\section{Standardized Work Concept}

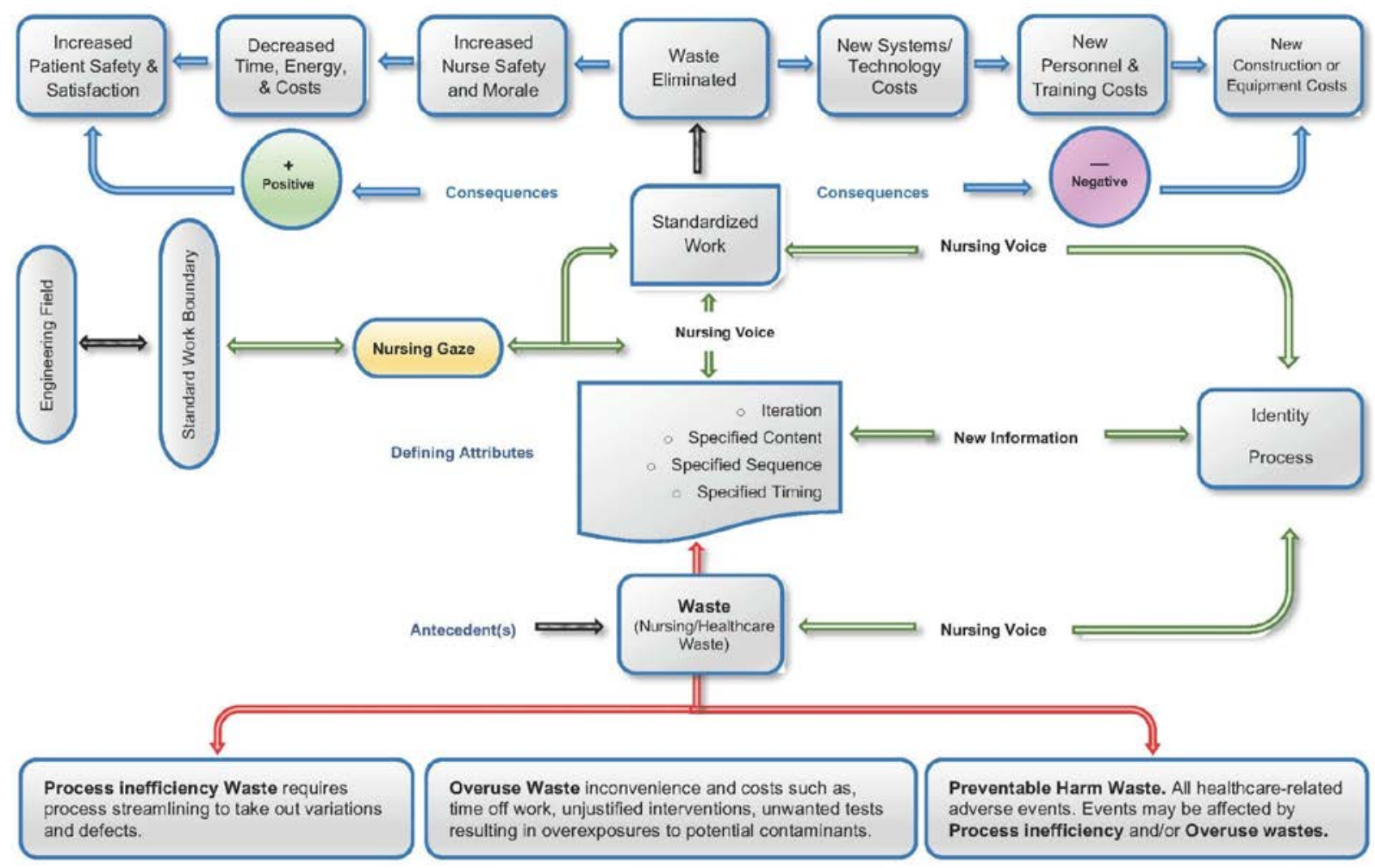




\section{Appendix B}

\section{Donabedian's Systems Model}

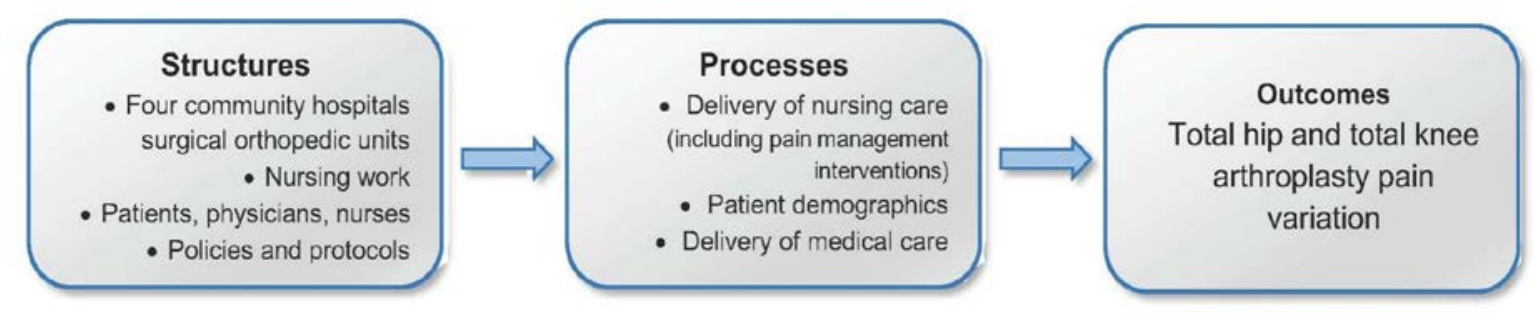

Donabedian conceptual model to evaluate pain variation in patients during hospitalization after total hip or total knee arthroplasty. Adapted from Donabedian, A. (2002). An introduction to quality assurance in health care. New York, NY: Oxford University Press. 
Appendix C

Pain Theory $3^{\text {rd }}$ Paradigm

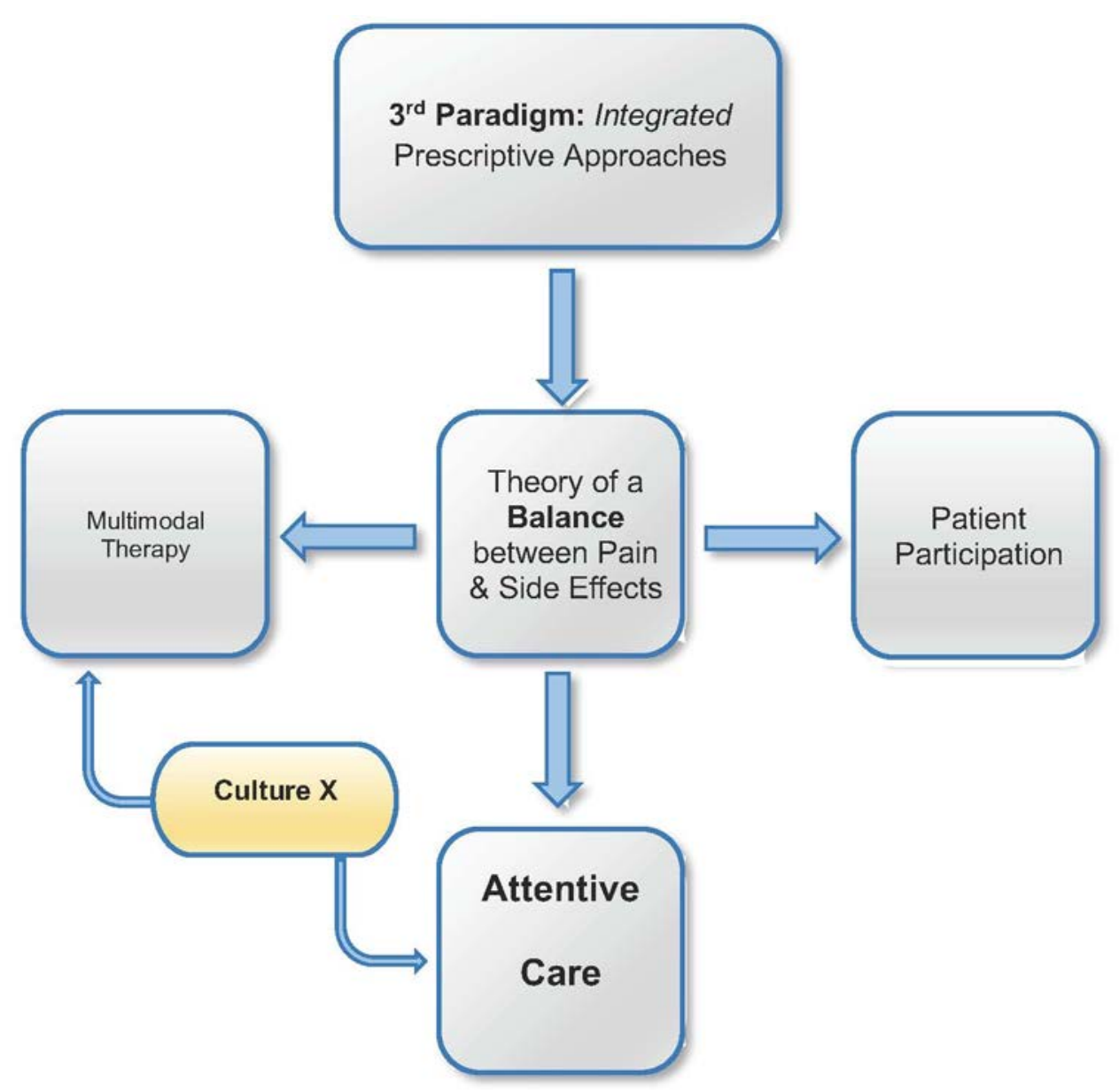

Pain theory: $3^{\text {rd }}$ paradigm. Adapted from Good, M. (2004). Pain: A balance between analgesia and side effects. In S. J. \& T. S. Bredow (Eds.), Middle range theories application to nursing research (2nd ed., pp. 63-81). Philadelphia, PA: Wolters Kluwer. 


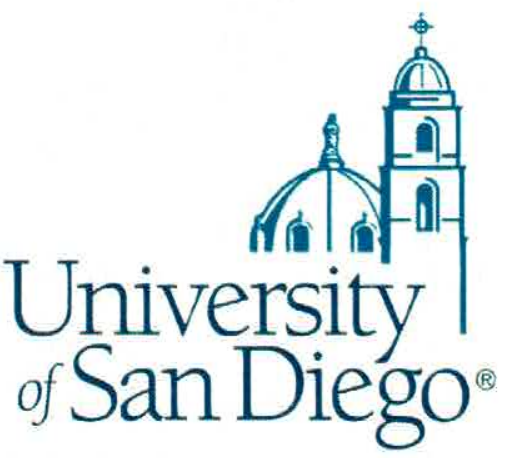

Sep 5, 2017 12:00 PM PDT

Melodie Daniels

Hahn School of Nursing \& Health Science

Re: Expedited - Initial - IRB-2018-2, Identification of nurse-controlled predictors of pain in patients undergoing a total hip or a total knee arthroplasty

Dear Melodie Daniels:

The Institutional Review Board has rendered the decision below for IRB-2018-2, Identification of nurse-controlled predictors of pain in patients undergoing a total hip or a total knee arthroplasty.

Decision: Exempt

Selected Category: Category 4. Research involving the collection or study of existing data, documents, records, pathological specimens, or diagnostic specimens, if these sources are publicly available or if the information is recorded by the investigator in such a manner that subjects cannot be identified, directly or through identifiers linked to the subjects.

Findings: None

Research Notes:

Internal Notes:

Note: We send IRB correspondence regarding student research to the faculty advisor, who bears the ultimate responsibility for the conduct of the research. We request that the faculty advisor share this correspondence with the student researcher.

The next deadline for submitting project proposals to the Provost's Office for full review is N/A. You may submit a project proposal for expedited or exempt review at any time.

Sincerely,

Dr. Thomas R. Herrinton

Administrator, Institutional Review Board

Office of the Vice President and Provost

Hughes Administration Center, Room 214

5998 Alcalá Park, San Diego, CA $92110-2492$

Phone (619) 260-4553 • Fax (619) 260-2210 •

www.sandiego.edu 